\title{
Sonic hedgehog negatively regulates pre-TCR-induced differentiation by a Gli2-dependent mechanism
}

\author{
Nicola J. Rowbotham, ${ }^{1}$ Ariadne L. Hager-Theodorides,,${ }^{1}$ Anna L. Furmanski, ${ }^{1}$ Susan E. Ross, ${ }^{1}$ Susan V. Outram, ${ }^{1}$ \\ Johannes T. Dessens, ${ }^{2}$ and Tessa Crompton ${ }^{1}$ \\ ${ }^{1}$ Immunobiology Unit, Univeristy College London Institute of Child Health, London; and 2Department of Infectious and Tropical Diseases, London School of \\ Hygiene \& Tropical Medicine, London, United Kingdom
}

\begin{abstract}
Hedgehog signaling regulates differentiation, survival, and proliferation of the earliest double-negative (DN) thymocytes, but its importance at later stages of T-cell development is controversial. Here we use loss- and gain-of-function mouse models to show that Shh, by signaling directly to the developing thymocyte, is a negative regulator of pre-TCR-induced
\end{abstract}

differentiation from DN to double-positive (DP) cell. When hedgehog signaling was reduced, in the $\mathrm{Shh}^{-1-}$ and $\mathrm{Gli}^{-I-}$ thymus, or by $\mathrm{T}$ lineage-specific transgenic expression of a transcriptional-repressor form of Gli2 (Gli2 $\Delta \mathrm{C}_{2}$ ), differentiation to DP cell after pre-TCR signal transduction was increased. In contrast, when Hh signaling was constitutively activated in thy- mocytes, by transgenic expression of a constitutive transcriptional-activator form of Gli2 $\left(\mathrm{Gli} 2 \Delta \mathrm{N}_{2}\right)$, the production of DP cells was decreased. Gene expression profiling showed that physiologic Hh signaling in thymocytes maintains expression of the transcription factor FoxA2 on pre-TCR signal transduction. (Blood. 2009;113:5144-5156)

\section{Introduction}

The thymus provides a specialized environment that supports the maturation of lymphocyte precursors into functional $\mathrm{T}$ cells, and one factor from the thymic epithelium that signals to developing thymocytes is the secreted intercellular signaling protein Sonic hedgehog (Shh). ${ }^{1}$ Shh, one of 3 mammalian hedgehog (Hh) proteins, is a morphogen essential for embryogenesis, ${ }^{2-4}$ and homeostasis of adult tissues. ${ }^{5,6}$ The mammalian Hh proteins trigger a common signaling pathway: They bind their cell-surface receptor Patched, which on Hh interaction releases the Hh-signal transduction molecule Smoothened (Smo) from inhibition, and Smo activates members of the Gli family of transcription factors, Gli1, Gli2, and Gli3. 3,7,8 The Gli proteins bind DNA in a sequencespecific manner and have specialized functions and distinct temporal and spatial expression patterns. ${ }^{9,10}$ On Hh signal transduction, they are transported to the nucleus to promote target-gene transcription. Gli1 acts only as a transcriptional activator and is not essential for mouse development. ${ }^{11}$ Gli2 and Gli3 can be processed to function as transcriptional activators or transcriptional repressors. ${ }^{12,13}$ In the absence of Hh signaling, Gli2 and Gli3 undergo modification by phosphorylation and cleavage of their C-terminal transactivation domain to function as transcriptional repressors. ${ }^{9,10}$

Gli2 and Gli3 are essential for mouse development and have distinct, and partially overlapping, functions. ${ }^{14}$ Although Gli2 and Gli3 are bifunctional, Gli2 acts in vivo primarily as a transcriptional activator and is necessary to initiate the first transcriptional changes on $\mathrm{Hh}$ signal transduction, ${ }^{15}$ whereas Gli3 functions mainly as a negative regulator of transcription..$^{15,16}$

During T-cell development, thymocytes pass through developmental stages defined by expression of cell-surface markers. $\mathrm{CD}^{-}{ }^{-} \mathrm{CD} 8^{-}$double-negative $(\mathrm{DN})$ thymocytes differentiate into $\mathrm{CD} 4{ }^{+} \mathrm{CD} 8{ }^{+}$double-positive (DP) thymocytes, which then mature into $\mathrm{CD}^{+}{ }^{+}$or $\mathrm{CD}^{+}$single-positive cells. The $\mathrm{DN}$ population can be further subdivided: the most immature population expresses CD44 but not CD25 (DN1). As these thymocytes mature they gain CD25 expression (DN2), then lose CD44 expression (DN3), eventually becoming negative for both CD44 and CD25 (DN4) before differentiating into $\mathrm{DP}$, often via an immature $\mathrm{CD} 8^{+}$ intermediate (CD8ISP).

During the DN3 stage, the TCR $\beta$ chain locus is rearranged. Cells that successfully rearrange a TCR $\beta$ allele and express a functional TCR $\beta$ chain signal through the pre-TCR, causing rearrangement of the other TCR $\beta$ locus to be suppressed (allelic exclusion), rescue from apoptosis, proliferation. and up-regulation of CD4 and CD8 expression. This process, known collectively as $\beta$-selection, is necessary for the transition from DN to DP thymocyte. ${ }^{17}$

In the mouse thymus, Shh is expressed by some epithelial cells in the subcapsular region, medulla, and corticomedullary junction, and the molecules that allow a cell to respond to Shh are expressed by both lymphoid and stromal components. ${ }^{1,6,18-23}$ Analysis of mice mutant for Shh, Gli3, and Smo have shown that Hh signaling is necessary for efficient survival, proliferation, and differentiation of thymocytes at the transition from DN1 to DN2, ${ }^{18,21,22}$ but the role of $\mathrm{Hh}$ signaling at the transition from DN to DP thymocytes is controversial. Different experimental approaches have produced conflicting results that have led to 3 different interpretations: that Hh is a negative regulator of the pre-TCR signal and differentiation to $\mathrm{DP}^{6,21,24}$; that $\mathrm{Shh}$ is a positive regulator of the $\mathrm{DN}$ to $\mathrm{DP}$ transition ${ }^{18}$; or that $\mathrm{Hh}$ signaling does not influence thymocyte differentiation after the DN2 stage. ${ }^{22}$

In vitro studies first demonstrated that $\mathrm{Hh}$ signaling influences thymocyte development ${ }^{6,24}$ and suggested that Hh signaling was a negative regulator of differentiation to DP cell. Treatment of mouse fetal thymus organ cultures (FTOCs) with recombinant Shh protein arrested thymocyte development at the DN3 stage after TCR $\beta$
Submitted October 25, 2008; accepted March 6, 2009. Prepublished online as Blood First Edition paper, March 9, 2009; DOI 10.1182/blood-2008-10-185751.

The publication costs of this article were defrayed in part by page charge payment. Therefore, and solely to indicate this fact, this article is hereby marked "advertisement" in accordance with 18 USC section 1734.

(C) 2009 by The American Society of Hematology 
chain rearrangement, whereas neutralization of endogenous $\mathrm{Hh}$ signaling by anti-Hh antibody treatment increased DP production. ${ }^{6,18}$ In addition, in anti-CD3-treated Rag1 ${ }^{-1-}$ FTOCs, differentiation to DP was arrested or enhanced by Shh or anti-Hh treatment, respectively. ${ }^{6}$

In contrast to these in vitro experiments, ex vivo analysis of $\mathrm{Shh}^{-1-}$ fetal thymi on E16.5 suggested that Shh promotes differentiation to the DP stage, ${ }^{18}$ as both thymus size and the proportion of DP cells were greatly reduced. Analysis of Gli3 mutants showed that regulation of Hh signaling after pre-TCR signal transduction, via Gli3, is necessary for efficient transition from DN to DP. ${ }^{21}$ Depending on whether Gli3 is acting as an activator or repressor, the latter data support either a positive or negative role, respectively, for Hh signaling after pre-TCR signal transduction.

Finally, consistent with no role for $\mathrm{Hh}$ at the transition to DP cell, analysis of a conditional T lineage-specific Smo knockout model failed to reveal an influence of Hh after the DN2 stage. ${ }^{22}$ Lck-Cre-induced deletion of Smo reduced both the number and relative proportion of DP cells in the adult, but this reduction in DP cells was interpreted as the result of the earlier effects observed on the DN1 and DN2 populations, rather than an effect on or after pre-TCR signaling. In addition, in vivo anti-CD3-induced differentiation of $\operatorname{Rag} 1^{-1-}$ thymocytes produced similar numbers of DP cells, in both conditional Smo-deficient mice and littermates. ${ }^{22}$

These conflicting interpretations could reflect functional differences in the experimental models used, such as differences between the adult and fetal thymus, or in the case of the $\mathrm{Shh}^{-1-}$, systemic effects of the mutation on the developing embryo. Alternatively, the action of $\mathrm{Hh}$ signaling on differentiation to DP could be indirect through another cell type (eg, epithelium), so that when T lineagespecific mutants, such as the conditional Smo knockout, were analyzed no effect was observed. To reconcile all experimental data, we have proposed a model in which Shh promotes thymocyte differentiation before pre-TCR signaling, but negatively regulates differentiation to DP after pre-TCR signal transduction. ${ }^{1}$

Here, to resolve this controversy and provide further experimental evidence, we re-examine the transition from DN to DP in novel fetal and adult mouse models. By differentiating between events before and after pre-TCR signal transduction, we show that Shh, by signaling directly to the developing thymocyte, is a negative regulator of pre-TCR-induced differentiation to DP cell.

\section{Methods}

\section{Mice}

$\mathrm{Gli2}^{+/-}$mice ${ }^{14}$ and $\mathrm{Shh}^{+/-}$mice ${ }^{25}$ were on C57BL/6 background. lckGli2 $2 \Delta \mathrm{N}_{2}$ and $l c k$-Gli2 $\Delta \mathrm{C}_{2}$ transgenic mice were as described. ${ }^{20,26}$ For hydrocortisone $(\mathrm{HC})$ treatment, mice were injected intraperitoneally with $0.03 \mathrm{mg}$ per gram of body weight HC (Sigma-Aldrich, St Louis, MO) in $\mathrm{PB}$, and analyzed after 2 to 7 days. ${ }^{27}$ The United Kingdom Home Office (London, United Kingdom) approved mouse studies.

\section{PCR analysis}

DNA was extracted from tissue by digesting in lysis buffer containing $50 \mathrm{mM} \mathrm{KCl}, 1.5 \mathrm{mM} \mathrm{MgCL}_{2}, 10 \mathrm{mM}$ Tris HCL (pH 8.5), $0.01 \%$ gelatin, $0.45 \%$ Nonidet P-40, $0.45 \%$ Tween 20 , and $0.5 \mu \mathrm{g} / \mathrm{mL}$ proteinase $\mathrm{K}$ in water. Approximately $1 \mu \mathrm{g}$ DNA was used per polymerase chain reaction (PCR). Primers for Gli2 gene ${ }^{14}$ were oGli2 (Gli2WT) (5')AAACAAAGCTCCTGTCACG, (3')CACCCCAAAGCATGTGTTTT, OpPNT (Gli2mutated) (5')CACCCCAAAGCATGTGTTTT, (3')ATGCCTGCTCTTTACTGAAG.
Analysis of TCR $\beta$ gene rearrangement by quantitative PCR (Q-PCR), using $5^{\prime}$ primers to $V \beta 8.2$ and $V \beta 5.1$ and a $3^{\prime}$ primer to $J \beta 2.7$, was as described. $^{28}$

\section{Cell sorting}

DN1-4 populations were sorted, using anti-CD $25^{\mathrm{FITC}}$, $-\mathrm{CD} 4 / 8^{\mathrm{PE}}$, and

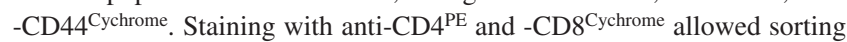
of DP and SPs, on MoFlo (Cytomation, Fort Collins, CO).

\section{QRT-PCR for Gli2 RNA expression}

RNA was extracted using Absolutely-RNA Miniprep kit (Stratagene, La Jolla, CA) from fluorescence-activated cell sorting (FACS)-sorted cells. cDNA was synthesized using Superscript-II (Invitrogen, Carlsbad, CA). Quantitative reverse-transcription (QRT)-PCR was as described, ${ }^{21}$ using primers Gli2F AGAACCTGAAGACACACCTGCG, Gli2R GAGGCATTGGAGAAGGCTTTG.

\section{Antibodies and flow cytometry}

Cells were stained as described ${ }^{21}$ using directly conjugated antibodies from BD PharMingen (San Diego, CA) and analyzed on a FACScan (BD Biosciences). Live cells were gated by FSC/SSC profiles. Data represent more than 3 experiments.

Intracellular staining for $\mathrm{TCR} \beta^{27}$ and phospho-Erk ${ }^{29}$ were as described.

\section{FTOC}

FTOC was as described ${ }^{6}$ with azide-free anti-CD $3 €$ monoclonal antibody (mab) treatment where stated.

\section{PCR arrays with anti-CD3-treated Rag1 ${ }^{-I-}$ and Gli2 $\Delta \mathrm{C}_{2} \mathrm{Rag}^{-I-}$ thymocytes}

One lobe of each thymus was cultured overnight in AIM-V medium with $5 \mu \mathrm{g} / \mathrm{mL}$ anti-CD $3 \epsilon$. Thymocytes were extracted from the second, nontreated, control lobe. Thy $1.2^{+}$cells were separated using the EasySep system (StemCell Technologies, Vancouver, BC), following the manufacturer's instructions. RNA was extracted using Absolutely-RNA kit (Stratagene) following the manufacturer's instructions.

Approximately $250 \mathrm{ng}$ RNA was used for cDNA synthesis using the RT $^{2}$ First strand kit (SuperArray Bioscience, Frederick, MD) following the manufacturer's instructions. cDNA synthesized was used for Mouse Signal Transduction PathwayFinder RT ${ }^{2}$ Profiler PCR Array (SA Biosciences, Frederick, MD). Three arrays were performed with preparations from each of $\mathrm{Rag}^{-1-}, \mathrm{Gli}_{2} \Delta \mathrm{C}_{2} \mathrm{Rag}^{-/-}$, $\mathrm{Rag} 1^{-1-}+$ anti-CD3-treated, and Gli2 $\Delta \mathrm{C}_{2} \mathrm{Rag}^{-1-}+$ anti-CD3-treated thymocyte samples. $\Delta \mathrm{Ct}$ values for each gene were obtained by subtracting the mean threshold cycle $(\mathrm{Ct})$ of the housekeeping genes (Gusb, HPRT, Hsp90ab1, and Actb) from the Ct value of the gene. Average $\Delta \mathrm{Ct}$ value for 3 experiments was calculated, for each gene, and average normalized transcription was calculated as follows: $2^{- \text {average } \Delta \mathrm{Ct}}$. Fold up- or down-regulation of transcription after anti-CD3 treatment was calculated by dividing the average normalized transcription of each gene in the test samples (Rag1 ${ }^{-/-}+$anti-CD3 or Gli2 $\Delta \mathrm{C}_{2} \mathrm{Rag}^{-/-}+$ anti-CD3) by the corresponding control ( $\operatorname{Rag} 1^{-/-}$or $\mathrm{Gli} 2 \Delta \mathrm{C}_{2} \operatorname{Rag} 1^{-/-}$) value. Statistical significance in up- or down-regulation of transcription was determined by Student $t$ test (paired, 2-tailed), comparing the $\Delta \mathrm{Ct}$ values, for each gene, before and after treatment from the 3 experiments performed for $\mathrm{Rag} 1^{-1-}$ or $\mathrm{Gli} 2 \Delta \mathrm{C}_{2} \mathrm{Rag} 1^{-/-}$genotypes. To determine significant differences in the response in anti-CD3 treatment between $\mathrm{Rag} 1^{-/-}$and Gli $2 \Delta \mathrm{C}_{2} \mathrm{Rag}^{-1-}$ thymocytes, we performed Student $t$ test (2-sample, equal variance, 2-tailed distribution) for each gene comparing the $\Delta \Delta \mathrm{Ct}$ $\left(\Delta \Delta \mathrm{Ct}=\Delta \mathrm{Ct}_{\text {ant-CD3 treated }}-\Delta \mathrm{Ct}_{\text {control }}\right)$ values from the 3 experiments. Significant differences were identified when $P$ was less than .05 . 


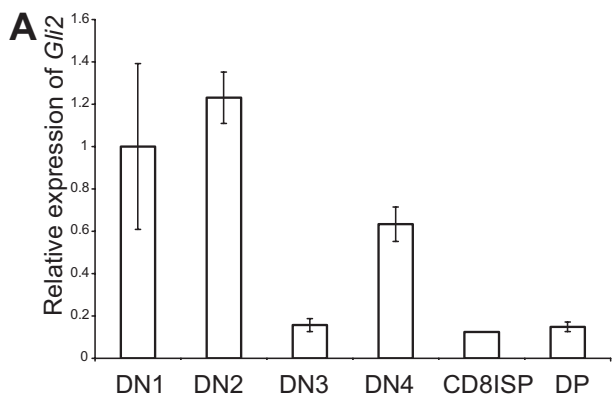

\section{B E13.5}

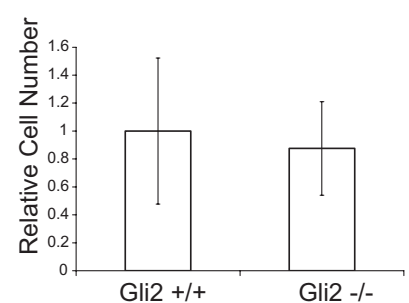

C $E 14.5$

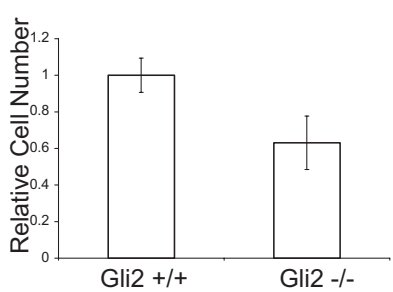

Gli2+/+

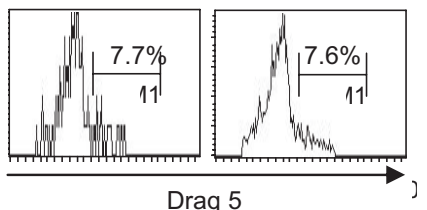

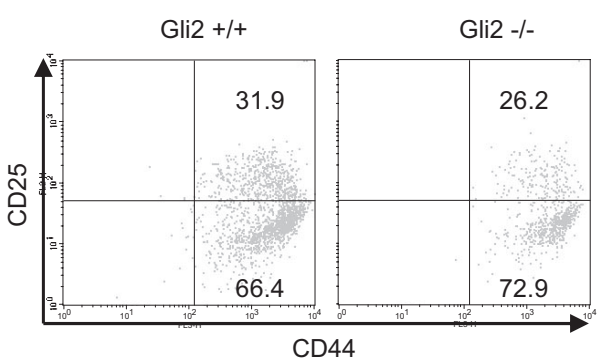

Gli2+/+

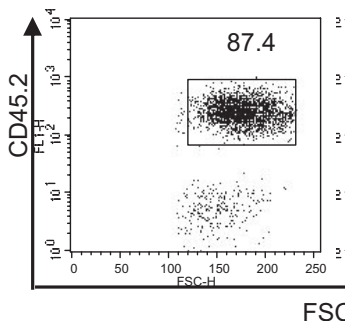

FSC

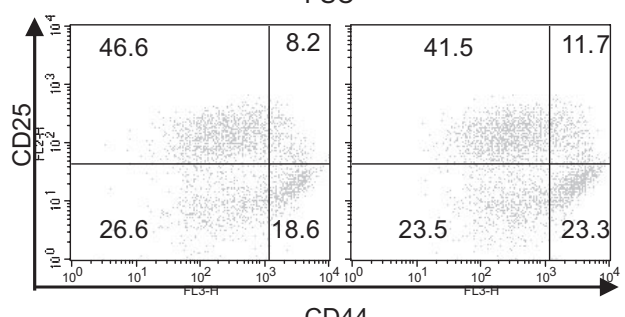

CD44

Gli2-/-

86.1
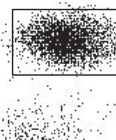

sin

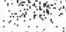

(n)

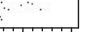

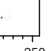

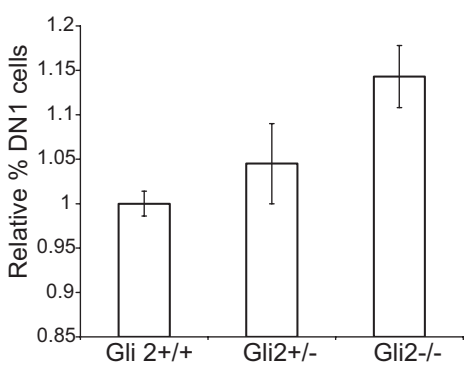

(1)

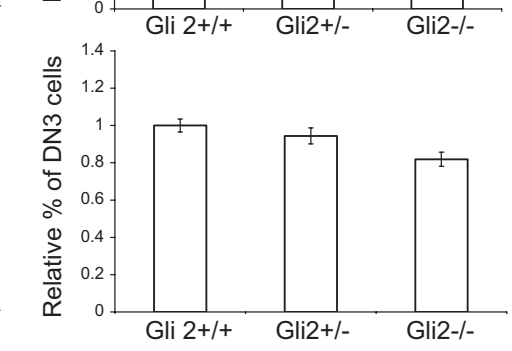

Figure 1. Gli2 expression in thymocytes on E16.5, and function in E13.5 and E14.5 thymus. (A) Gli2 expression in sorted C57BL/6 E16.5 thymocytes. Error bars represent SD. (B) Gli2 affects the transition from DN1 to DN2 in E13.5 embryos (WT, $n=5 ; \mathrm{Gli2}^{+/-}, \mathrm{n}=12 ; \mathrm{Gli2}{ }^{-/-}, \mathrm{n}=8$ ). Relative number of thymocytes on E13.5. To allow comparison between litters, the number of cells in each thymus was divided by the mean of WT littermates to give a relative cell number for each thymus. Dot plots show DN subset composition of E13.5 thymi. Cells were gated for CD45.2 $2^{+}$, and analyzed by CD25 and CD44 expression. Bar chart shows the relative percentage of DN1 cells in E13.5 thymi. The difference between WT and Gli2 ${ }^{-1-}$ is statistically significant $(P=.02)$. (C) Thymocyte development in $\mathrm{E} 14.5 \mathrm{Gli2}{ }^{-1-}$ and littermate embryos $\left(\mathrm{WT}\right.$, $\mathrm{n}=17 ; \mathrm{Gli2}^{+/-}$, $\mathrm{n}=27$; Gli2 $\left.{ }^{-1-}, \mathrm{n}=15\right)$. Bar chart shows the relative thymocyte number on E14.5. The difference between WT and Gli2 ${ }^{-1-}$ is significant $(P=.04)$. Top dot plot shows $\mathrm{E} 14.5$ thymocytes stained with anti-CD45.2. Cells positive for CD45.2+ were analyzed for CD25 and CD44 expression. Righthand bar charts show the relative percentage of DN1 and DN3 cells in E14.5 thymi. Differences in mean relative percentages of DN1 and DN3 populations were statistically significant between WT and Gli2 ${ }^{-/-}(P=.04$ and $P=.002$, respectively). Histograms show Draq5 staining of E14.5 thymocytes. The percentage of cells in G2+S/M is given.

\section{Results}

\section{Gli2 is expressed differentially in fetal DN subsets}

Gli2 is essential to initiate the Hh signal and activate transcription of target genes. ${ }^{15}$ Therefore, to investigate the function of $\mathrm{Hh}$ pathway activation in developing DN cells, we followed thymocyte development in Gli2 $2^{-1-}$ embryos on sequential embryonic days. Gli2-deficient embryos die just before birth, and in contrast to $\mathrm{Shh}^{-1-}$ embryos, ${ }^{25}$ are of fairly normal size and appearance, ${ }^{14}$ so effects on thymocyte development are unlikely to be due to systemic differences in embryo growth or survival.
We analyzed the expression pattern of Gli2 in developing fetal thymocyte populations. Components of the Hh signaling pathway, including the Gli proteins, are differentially expressed in adult thymocyte populations. ${ }^{6,19-22}$ In the fetal thymus, Gli3 is differentially expressed in DN cells, with expression in the DN1 population, down-regulation in the subsequent DN2 and DN3 stages, and highest expression in the DN4 population. ${ }^{21}$

Thymocyte populations were FACS-sorted from E16.5 fetal thymi and transcription of Gli2 was analyzed by QRT-PCR (Figure 1A). Gli2 was most highly expressed in DN1 and DN2 cells, down-regulated at the DN3 stage, and up-regulated more than 3 -fold in the DN4 population. This expression pattern suggests that 
A
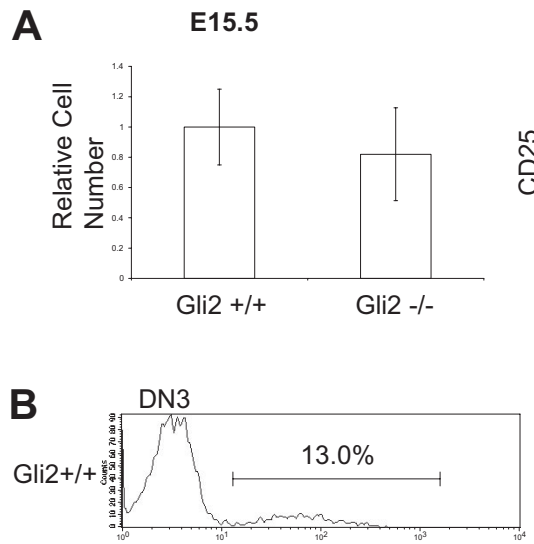

Gli2-/-

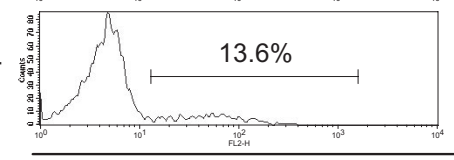

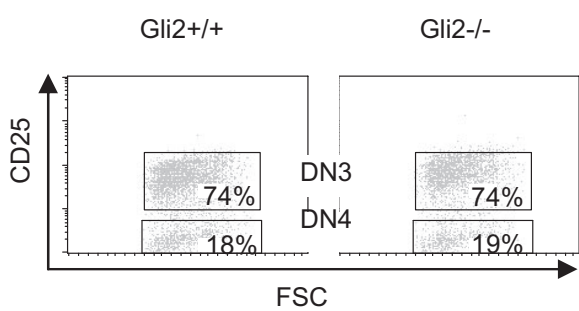

FSC
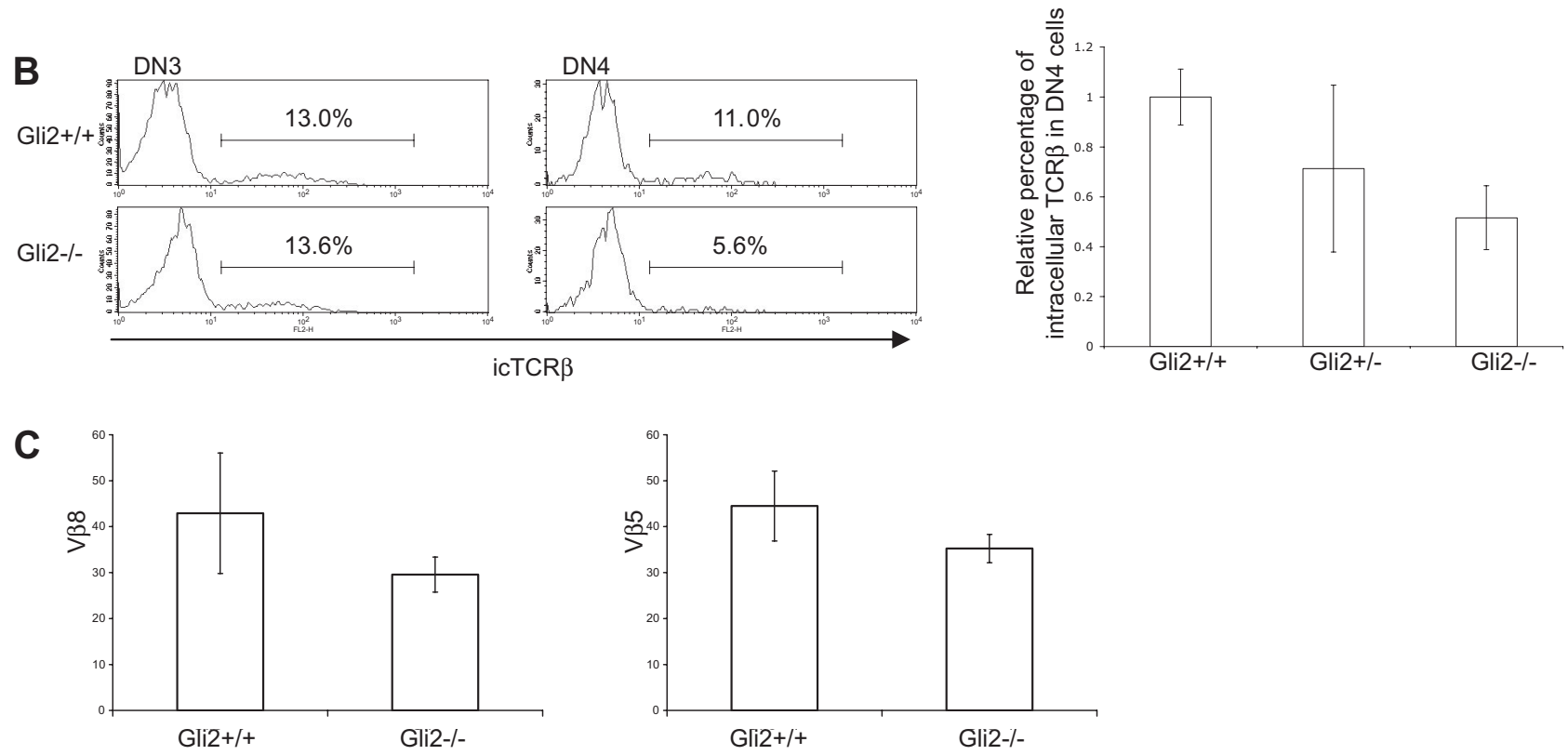

Figure 2. Gli2 function in the E15.5 thymus. (A) Phenotype of E15.5 Gli2 ${ }^{-/-}$thymi (WT, $n=8 ; \mathrm{Gli}^{+/-}, \mathrm{n}=9$; Gli2 ${ }^{-/-}$, $\mathrm{n}=7$ ). Bar chart shows the relative number of thymocytes on E15.5; error bars are SD. The difference between WT and Gli2 ${ }^{-1-}$ was not statistically significant. Dot plot shows the relative proportions of DN3 and DN4 populations: Cells negative for CD3, CD4, CD8, and CD44 were analyzed for CD25 expression. Cells positive for CD25 (DN3) and negative for CD25 (DN4) were gated separately. There were no significant differences in the proportion of DN3 and DN4 cells on E15.5. (B) Intracellular TCR 3 (icTCR $\beta$ ) expression in the E15.5 WT and Gli2 ${ }^{-1-}$ thymus. Histogram plots of icTCR $\beta$ staining gated on DN3 (left) and DN4 (right) cells. Bar chart shows the relative percentage of icTCR $\beta$ on DN4 cells in E15.5 thymi. The difference between WT and Gli2 ${ }^{-1-}$ was statistically significant $(P=.02)$. (C) Bar charts to show degree of $V \beta 8$ to J $\beta 2.7$ (left chart) and $V \beta 5$ to J $\beta 2.7$ (right chart) rearrangement in E15.5 WT and $\mathrm{Gli}^{-/-}$thymocytes, assessed by Q-PCR.

Gli2 is likely to function early in thymocyte development at DN1/DN2 (as has been shown for Shh, Gli3, and Smo ${ }^{18,21,22}$ ) and in the DN4 population. We therefore assessed the impact of Gli2 mutation on these 2 developmental stages by analyzing thymocyte development from E13.5 to just before birth.

\section{Inefficient differentiation from DN1 to DN2 in $\mathrm{Gli}^{-1-}$ thymus}

In embryos, thymocyte development occurs in a more or less synchronized wave facilitating analysis of specific stages of development on different embryonic days, and on E13.5 the majority of cells are DN1 and DN2 (Figure 1B). On E13.5, the difference in cell number between $\mathrm{Gli}^{-1-}$ and WT littermate thymi was not significant (Figure 1B), but the proportion of DN1 cells was significantly increased $(P=.02)$ in the $\mathrm{Gli}^{-/-}$compared with WT (Figure 1B), and the proportion of DN2 cells was concomitantly decreased. There were no differences in anti-ckit or antiB220 staining on the $\mathrm{CD} 45^{+} \mathrm{CD} 44^{+}$population between $\mathrm{WT}$ and Gli2 $^{-1-}$ (data not shown).

We assessed thymocyte development on E14.5, to ask whether the inefficient DN1 to DN2 transition observed on E13.5 impacted on subsequent developmental stages. On E14.5, thymocyte number was significantly reduced, and in addition to the increase in the DN1 population, the proportion of DN3 cells was significantly reduced, indicative of a developmental delay (Figure 1C). There was no significant difference in the proportion of thymocytes in $\mathrm{G} 2+\mathrm{S} / \mathrm{M}$ as assessed by Draq5 staining (Figure 1C).

On E15.5 there was no significant difference in cell number, or in the proportions of DN3 or DN4 cells (Figure 2A). To test for TCR $\beta$ expression, we measured intracellular TCR $\beta$ (icTCR $\beta$ ) protein in DN populations. In the DN3 population, the proportion of icTCR $\beta^{+}$was similar for both the Gli $2^{-1-}$ and WT littermates, typically around $13 \%$ (Figure $2 \mathrm{~B}$ ). In contrast, the proportion of icTCR $\beta^{+}$cells was reduced in the Gli2 ${ }^{-1-}$ DN4 population compared with WT (Figure 2B). During fetal thymocyte development, TCR $\beta$ expression is not necessary for transition from DN3 to DN4 and the majority of the DN4 population do not express icTCR $\beta$ until E17.5. ${ }^{27}$ We therefore measured TCR $\beta$ gene rearrangement using a Q-PCR assay, ${ }^{28}$ using $5^{\prime}$ primers to $V \beta 8.2$ and $V \beta 5.1$ and a $3^{\prime}$ primer to $J \beta 2.7$ (Figure $2 \mathrm{C}$ ). We did not detect a statistically significant reduction in either $V \beta 8.2$ to $J \beta 2.7$ or $V \beta 5.1$ to $J \beta 2.7$ rearrangement in the $\mathrm{Gli}^{-/-} \mathrm{DN}$ cells, relative to WT, suggesting that the reduction in icTCR $\beta$ staining in the DN4 population was most likely the consequence of delayed progression of thymocyte development.

\section{Reduced transition from DN to DP in $\mathrm{E}_{16.5} \mathrm{Gli2}^{-1-}$ mice}

DP cells first appear on E16.5, so to assess the impact of Gli2 mutation on differentiation to DP we analyzed E16.5 $\mathrm{Gli}^{-/-}$ 
From www.bloodjournal.org by guest on August 22, 2019. For personal use only.

A $\quad$ E16.5
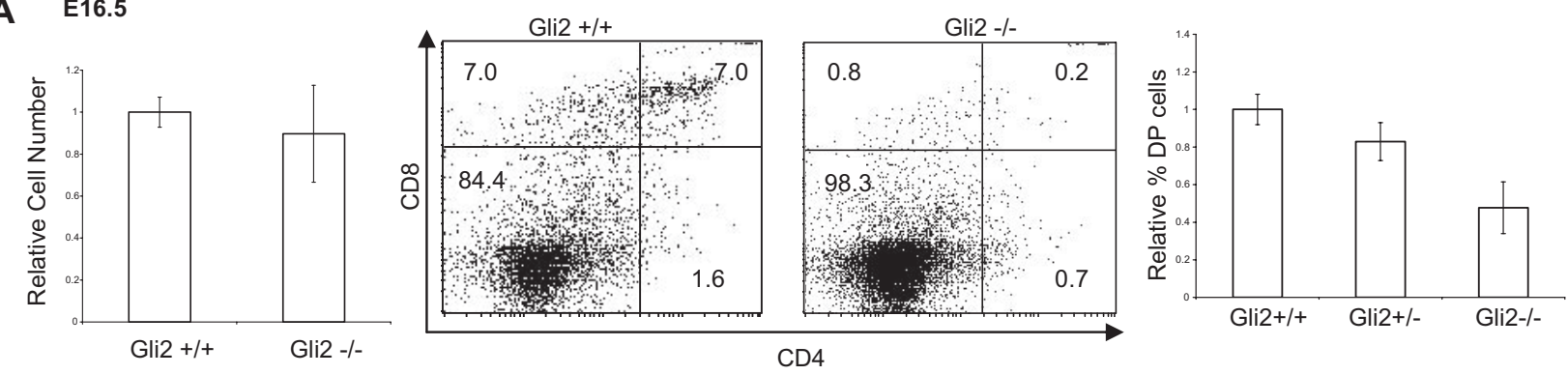

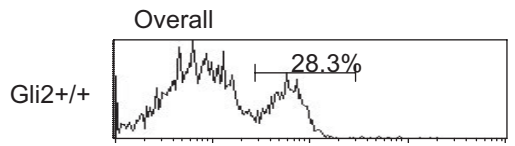

Gil2-1

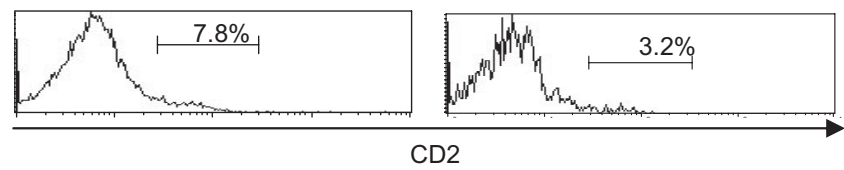

B

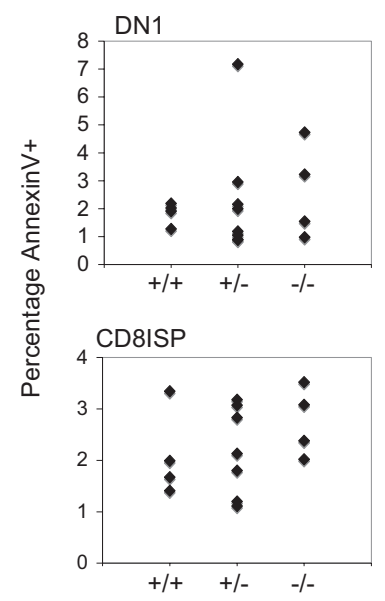

DN

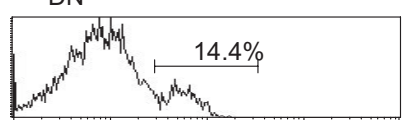

CD25+DN
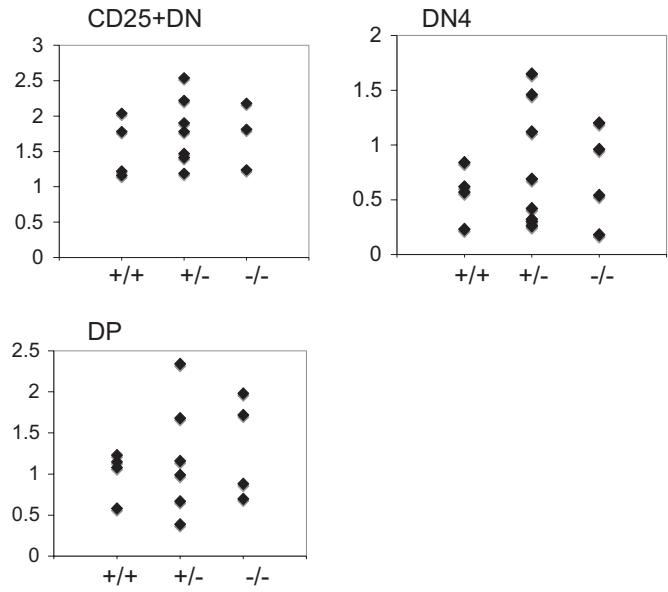

C $\quad \mathrm{E} 17.5$

Gli2+/+

Gli2-/-
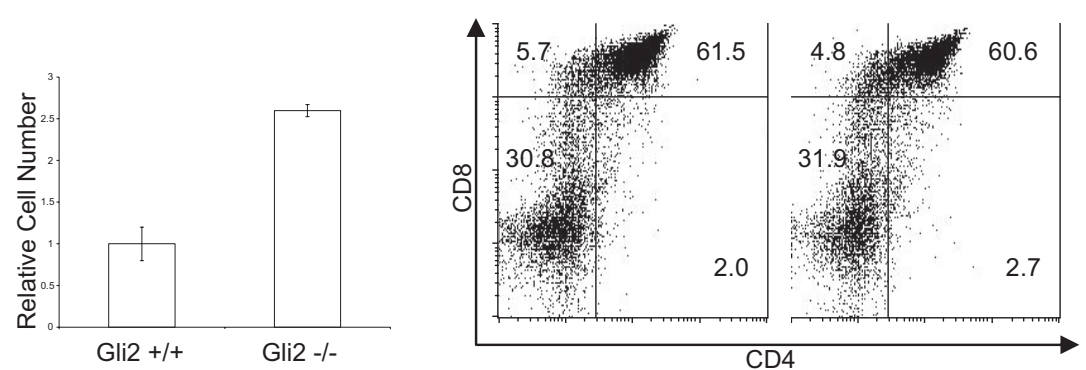

D

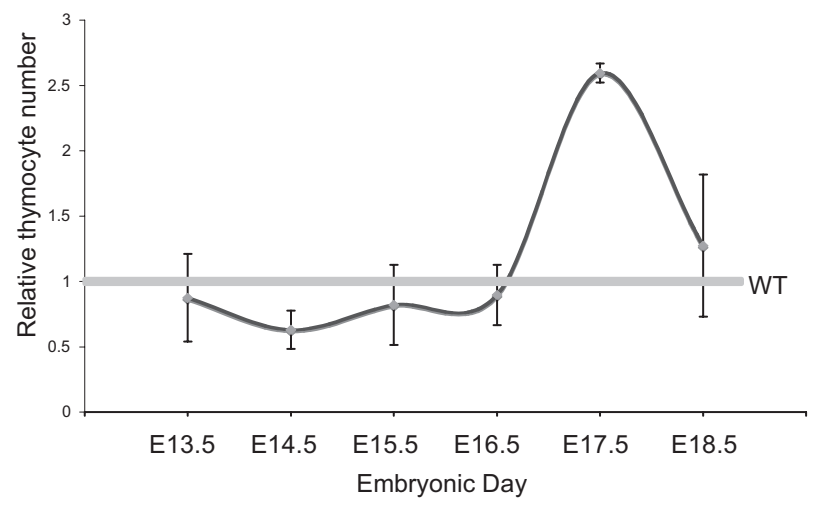

Figure 3. 
thymi. There was no significant difference in thymocyte number on E16.5 between the Gli2 ${ }^{-1-}$ and WT littermates, but the proportions of DP and ISP cells were significantly reduced (Figure 3A), and the DN population was increased.

We also found a reduction in the developmentally regulated marker CD2. ${ }^{30,31}$ In Gli2 ${ }^{-1-}$ thymocytes, cell-surface expression of $\mathrm{CD} 2$ was reduced from $28.3 \%$ in WT to $7.8 \%$. This reduction did not simply reflect the decrease in DP cells, as when we gated on the DN population CD2 expression was reduced from $14.4 \%$ to $3.2 \%$ (Figure 3A).

Given that we were unable to detect a difference in cell-cycle status between Gli2 $2^{-1-}$ and WT in the DN populations (Figure 1C), but the number of DP and ISP cells was reduced relative to WT in the E16.5 Gli2 $2^{-1-}$ thymus, we asked whether Gli2 is necessary for efficient survival of DN, ISP, or DP populations. We assessed apoptosis by annexin V staining in DN1, CD25 ${ }^{+} \mathrm{DN}$, DN4, CD8ISP, and DP populations on E16.5 (Figure 3B). We found no significant differences in the mean percentages of annexin $\mathrm{V}^{+}$cells between E16.5 WT, Gli2 ${ }^{+/-}$, and Gli2 ${ }^{-1-}$ littermates in any thymocyte population. This is in contrast to the $\mathrm{Shh}^{-1-}$ thymus, in which apoptosis is increased relative to WT in the E16.5 DN4 population, ${ }^{18}$ and suggests that the functions of Gli2 downstream of Shh signaling in thymocytes are partially redundant with Gli1 or Gli3, as has been shown in other tissues. ${ }^{14}$

\section{Accelerated differentiation to DP population after pre-TCR signaling}

As we found that Gli2 was not necessary for thymocyte survival (Figure 3B), it seemed likely that the reduction in the DP population observed on E16.5 was a consequence of an earlier requirement of Gli2 (and $\mathrm{Hh}$ signaling). We therefore asked whether the DP population could recover. On E17.5 there were approximately 2.5 times more DP thymocytes in the Gli2 $2^{-1-}$ thymus than in WT $(P=.025$; Figure $3 \mathrm{C})$, indicating that after pre-TCR signal transduction, Gli2 ${ }^{-/-}$thymocytes expand and differentiate more quickly than their WT counterparts.

From E13.5 to E16.5 the Gli2 ${ }^{-1-}$ thymus was on average slightly smaller than that of WT littermates, but by E17.5 it rapidly expanded to contain 2.5-times more thymocytes than WT, and remained on average larger on E18.5 (Figure 3D). The expansion of the Gli2 deficient thymus corresponded to the day of embryonic development on which icTCR $\beta$ chain expression in the DN populations was approaching adult levels ${ }^{27}$ and capable of pre-TCR signal transduction. This presumably could not be detected on E16.5, because of low pre-TCR complex expression ${ }^{27}$ and the earlier developmental delay. These data indicate that $\mathrm{Hh}$ signaling, via Gli2, is a negative regulator of thymocyte expansion and differentiation to DP cell, after pre-TCR signal transduction, during fetal development (Figure 3D).

\section{Hh pathway activation impedes reconstitution of the DP pool in adult mice}

Analysis of T-lineage-specific Smo conditional knockout mice has not revealed an influence of $\mathrm{Hh}$ signaling at the transition from $\mathrm{DN}$ to DP in the adult thymus, ${ }^{22}$ but this ex vivo analysis of Gli2-/embryonic thymus and previous in vitro experiments using fetal thymus have indicated that $\mathrm{Hh}$ signaling is a negative regulator of

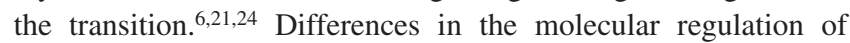
thymocyte development between adult and fetus might account for this discrepancy. We therefore investigated the impact of $\mathrm{Hh}$ signaling on the production of DP cells in the adult thymus. Gli2-deficient embryos die before birth, ${ }^{14}$ so we used mouse models in which Hh signaling is specifically repressed or activated in T-lineage cells, by transgenic expression of activator-only or repressor-only truncated forms of Gli2, under the control of the $l c k$ promotor. ${ }^{13,20,26,32}$ Our earlier work showed that these transgenics were successful at up-regulating $\left(\mathrm{Gli} 2 \Delta \mathrm{N}_{2}\right.$ [constitutively active $\mathrm{Hh}$ signal]) or down-regulating ( $\mathrm{Gli} 2 \Delta \mathrm{C}_{2}$ [constitutive repressor of Hh signaling]) Hh target genes in T-lineage cells. However, our previous studies of the Gli2 $\Delta \mathrm{N}_{2}$ and Gli2 $\Delta \mathrm{C}_{2}$ thymi had focused on later stages of T-cell development, and relative differences in the proportion of the DP population were small and were effected by changes at the DP to SP transition. ${ }^{20,26}$

Therefore, to examine differentiation from DN to DP in a synchronized wave, we used treatment with hydrocortisone (HC) to deplete the adult thymus by inducing apoptosis in all but the most mature cells. ${ }^{27}$ We then followed the recovery of the DP population, as the thymus grows to recover its normal size and subset distribution during the week after treatment. This strategy has previously been used to analyze the developmental sequence and timing of transition between thymocyte populations, ${ }^{27,33}$ allowing analysis of adult thymocyte differentiation in a synchronized wave, without resorting to the production of radiation chimeras. It facilitated detection of differences in the rate of differentiation to DP, which in adult mice is complicated by the fact that the adult thymus has reached steady state, so the transition is no longer synchronized, and there are pre-existing cells at all stages of development and homeostasis between populations. Adult Gli2 $\Delta \mathrm{N}_{2}$, Gli2 $\Delta C_{2}$, and their respective WT littermates were injected with $\mathrm{HC}$ and analyzed after 2 to 6 days (Figure 4).

In the case of the Gli $2 \Delta \mathrm{N}_{2}$ experiment, the DP population was depleted in both Gli $2 \Delta \mathrm{N}_{2}$ and WT littermates, to approximately $4 \%$ DP, with $7 \%$ to $8 \%$ DN, 2 days after $\mathrm{HC}$ treatment (Figure 4A). The Gli2 $\Delta \mathrm{N}_{2}$ thymi then produced DP cells at a slower rate than those of their WT littermates. Four days after HC treatment, the Gli2 $\Delta \mathrm{N}_{2}$ thymus contained $16.1 \%$ DP cells compared with $31.4 \%$ DP cells in the WT. After 5 days, production of DP cells in the Gli $2 \Delta \mathrm{N}_{2}$ transgenic was still significantly impeded $(P=.01)$ with the WT

\footnotetext{
Figure 3. Reduced transition from DN to DP in E16.5 Gli2 ${ }^{-/-}$mice. (A) Thymocyte development on E16.5 (WT, $\mathrm{n}=7$; Gli2 ${ }^{+/-}, \mathrm{n}=15 ; \mathrm{Gli2}{ }^{-/-}, \mathrm{n}=7$ ). Left bar chart shows relative number of thymocytes on E16.5. Error bars show SE. The difference between WT and Gli2 ${ }^{-1-}$ was not statistically significant. Dot plots show anti-CD4 and anti-CD8 staining on E16.5 thymocytes. Right bar chart shows the relative percentage of DP cells in E16.5 thymi. The difference between WT and Gli2 ${ }^{-/-}$was statistically significant $(P=.007)$. Histograms show CD2 expression in E16.5 thymi. Left panels: CD2 expression on all thymocytes. Right panels: CD2 expression on DN cells. The difference in percentage of $\mathrm{CD}^{+}$cells overall and on DN cells between Gli2 ${ }^{+/+}$and $\mathrm{Gli}^{-1-}$ thymi were statistically significant $(P=.01$ and $P=.04$, respectively). (B) Apoptosis in thymocyte populations on E16.5, measured by annexin V staining. Scatterplots show the percentage of annexin $\mathrm{V}^{+}$cells in DN1, CD25 ${ }^{+} \mathrm{DN}, \mathrm{DN} 4, \mathrm{CD} 8 \mathrm{ISP}$, and DP thymocyte populations in WT $(\mathrm{n}=4),+/-(\mathrm{n}=8)$, and $-/-(\mathrm{n}=4)$ embryos. Mean percentage positive was: DN1 WT, 1.85; +/-, 2.29; $-/-, 2.62$. CD25 + DN WT, 1.55; +/-, 1.79; $-/-$, 2.0. DN4 WT, $0.57 ;+/-, 0.78 ;-/-, 0.72$. CD8ISP WT, $2.10 ;+/-, 2.19 ;-/-, 2.75$. DP WT, $1.01 ;+/-, 1.21 ;-/-, 1.32$. There were no significant differences in the mean number of annexin $\mathrm{V}^{+}$cells between genotype of mice in any thymocyte population. (C) Thymocyte development on $\mathrm{E} 17.5\left(\mathrm{WT}, \mathrm{n}=7 ; \mathrm{Gli2}{ }^{+/-}, \mathrm{n}=4\right.$; $\mathrm{Gli2}{ }^{-/-}, \mathrm{n}=7$ ). Relative thymocyte number on E17.5. The difference between WT and Gli2 ${ }^{-1-}$ was statistically significant $(P=.02)$. Dot plots show anti-CD4 and anti-CD8 staining for E17.5 thymocytes. (D) Relative thymocyte number from E13.5 to E18.5, normalized to mean WT littermate value of $1.0 .\left(\right.$ For $E 18.5:$ WT, $n=5 ;$ Gli2 ${ }^{+/-}, n=5 ;$ Gli2 ${ }^{-/-}, n=5$.) Error bars show SD.
} 
From www.bloodjournal.org by guest on August 22, 2019. For personal use only.

A

2 days

4 days

5 days

6 days
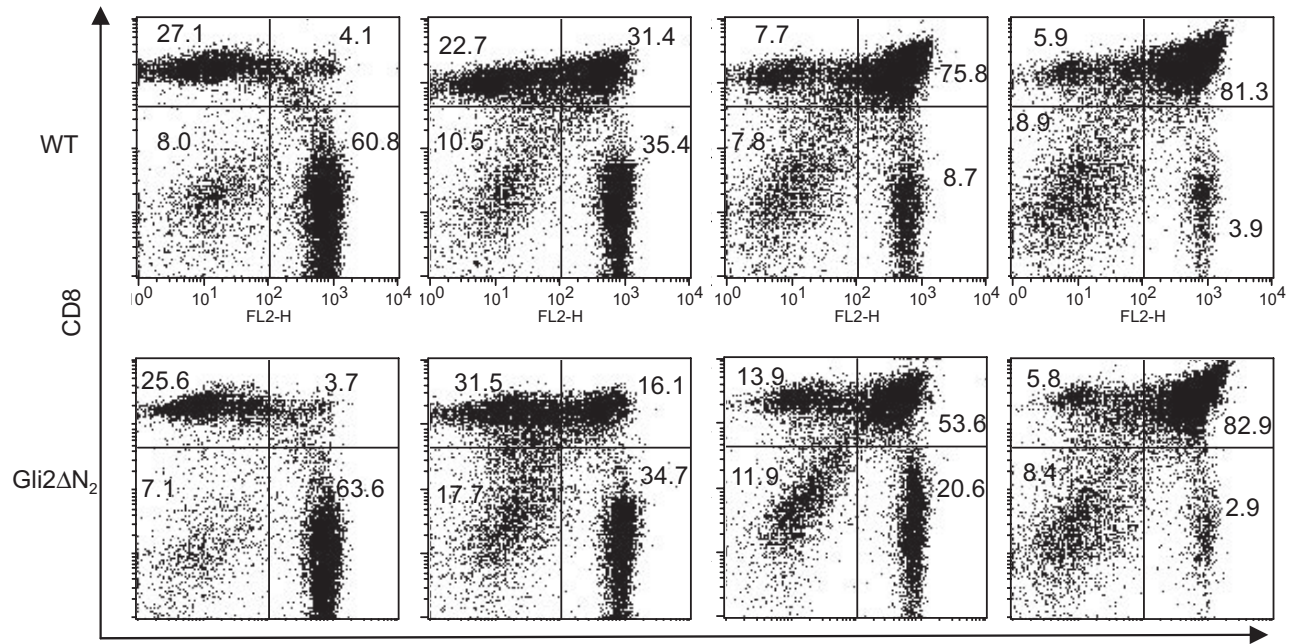

CD4

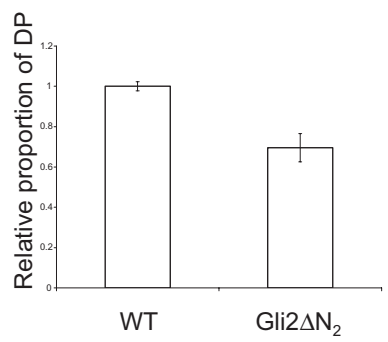

B
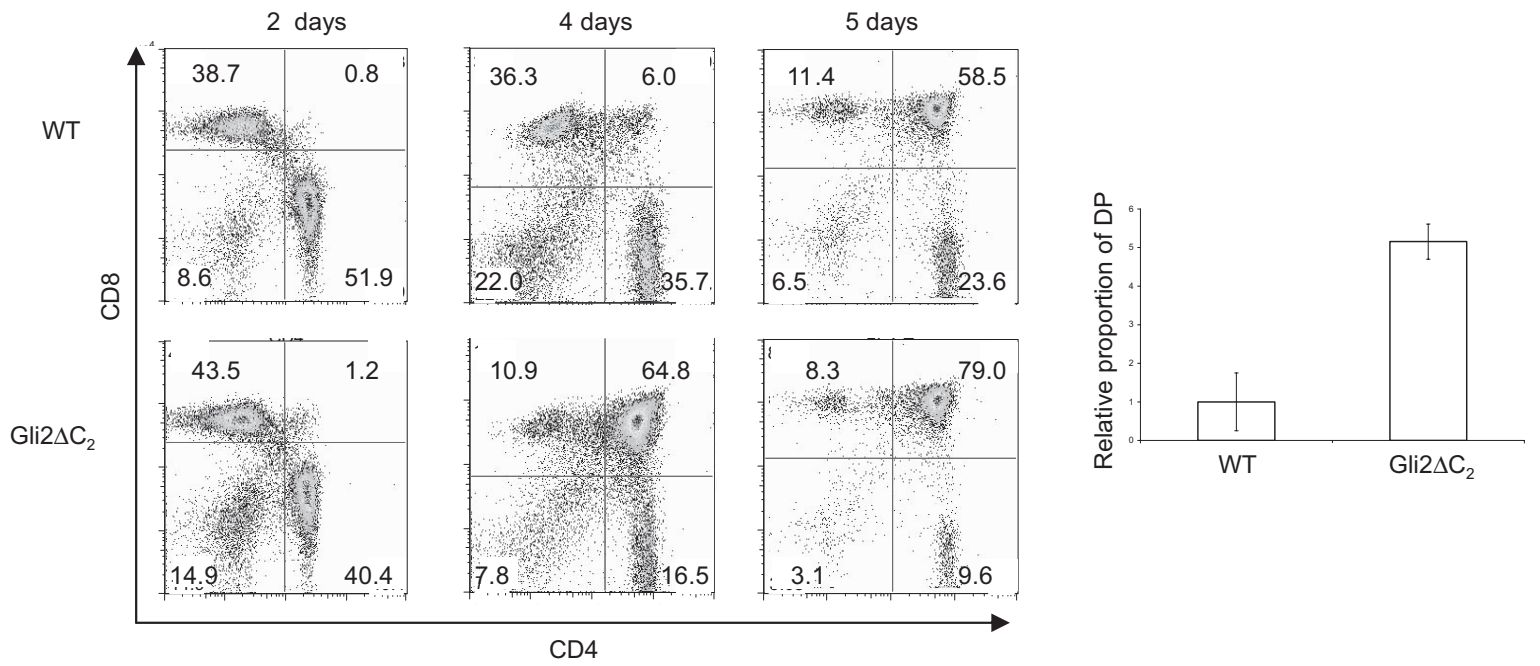

C

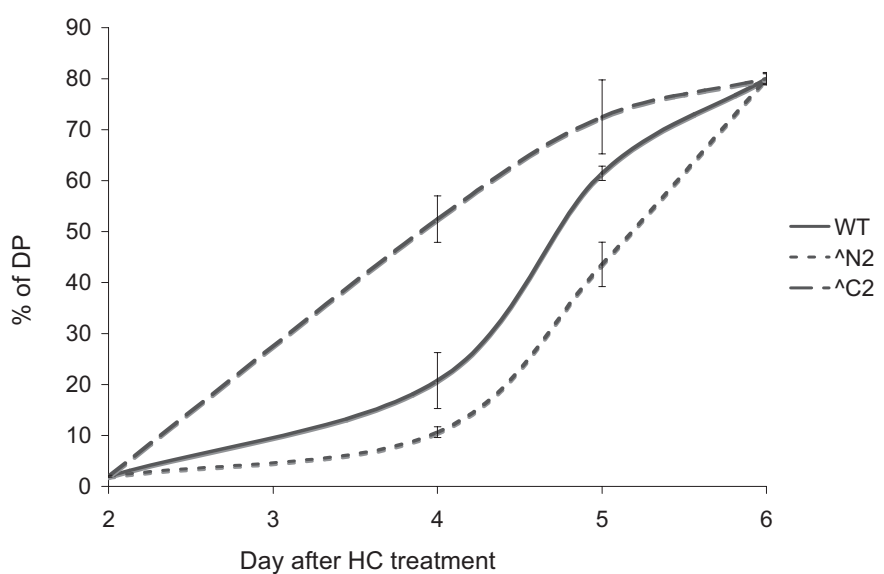

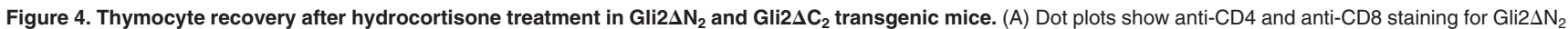
transgenic thymocytes and WT littermate thymocytes 2 to 6 days after treatment with HC. Bar chart shows the mean relative proportion of DP cells 5 days after HC treatment for WT and Gli2 $\Delta \mathrm{N}_{2}$ transgenic mice. The difference in mean percentage of DP cells was statistically significant $(P=.01)$. (B) Dot plots show anti-CD4 and anti-CD8 staining for Gli2 $\Delta \mathrm{C}_{2}$ transgenic thymocytes and WT littermate thymocytes 2 to 5 days after $\mathrm{HC}$ treatment. Bar chart shows the mean relative proportion of DP cells 4 days after HC treatment. The difference in DP percentage was statistically significant $(P=.004)$. (C) Graph of relative kinetics of DP recovery after $\mathrm{HC}$ treatment in WT, Gli2 $2 \mathrm{~N}_{2}$, and

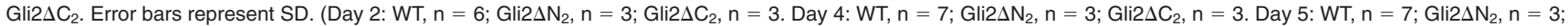
$\mathrm{Gli}_{2} \Delta \mathrm{C}_{2}, \mathrm{n}=3$. Day 6: WT, $\mathrm{n}=5 ; \mathrm{Gli}_{2} \Delta \mathrm{N}_{2}, \mathrm{n}=3 ; \mathrm{Gli}_{2} \Delta \mathrm{C}_{2}, \mathrm{n}=2$.) 
DP population recovering to around $75.7 \%$, compared with $53.7 \%$ in the Gli $2 \Delta \mathrm{N}_{2}$ transgenic (Figure $4 \mathrm{~A}$ ).

In contrast, the Gli $2 \Delta \mathrm{C}_{2}$ transgenic thymi produced DP cells more quickly than WT. In a typical experiment, the DP population was depleted 2 days after $\mathrm{HC}$ treatment, but after 4 days $64 \%$ of $\mathrm{Gli} 2 \Delta \mathrm{C}_{2}$ thymocytes were DP cells, compared with $6 \%$ of WT $(P=.004$; Figure 4B). After 5 days, the Gli $2 \Delta \mathrm{C}_{2}$ thymus contained a normal proportion of DP cells, compared with $58.5 \%$ in the WT (Figure 4B).

Six days after HC treatment, the DP populations in all genotypes of mice in all experiments had recovered to around $80 \%$ (Figure 4C). The relative kinetics of DP reconstitution after $\mathrm{HC}$ treatment (Figure 4C) demonstrated that whereas constitutive activation of $\mathrm{Hh}$ signaling $\left(\mathrm{Gli} 2 \Delta \mathrm{N}_{2}\right)$ impeded differentiation to $\mathrm{DP}$, repression of Hh signaling in thymocytes $\left(\mathrm{Gli} 2 \Delta \mathrm{C}_{2}\right)$ enhanced DP cell production, in the adult thymus in vivo.

\section{Hh signaling is a negative regulator of pre-TCR signal, reducing ERK phosphorylation}

Our data indicate that the $\mathrm{Hh}$ signaling pathway is a negative regulator of the transition from DN to DP in vivo in both the fetal and adult thymus. As pre-TCR signal transduction is essential for this stage of development, we used Rag $1^{-1-}$ E15.5 FTOC in which anti-CD3 mab treatment mimics the pre-TCR signal, ${ }^{34,35}$ to investigate the impact of $\mathrm{Hh}$ signaling on pre-TCR signal transduction. We treated $\mathrm{Shh}^{-1-} \mathrm{Rag}^{-1-}$ and $\mathrm{Rag} 1^{-/-}$littermate FTOC with anti-CD3 and analyzed differentiation to DP after 3 days. Consistent with the phenotype of E13.5 $\mathrm{Shh}^{-1-} \mathrm{Rag}^{+/+}$embryos, ${ }^{18}$ before culture the $\mathrm{Shh}^{-1-} \mathrm{Rag} 1^{-1-}$ thymi were smaller and contained a greater proportion of DN1 cells than $\mathrm{Rag} 1^{-/-}$littermate thymi (Figure 5A). Propidium iodide staining showed that fewer thymocytes were in $\mathrm{S}+\mathrm{G} 2 / \mathrm{M}$ in the $\mathrm{Shh}^{-1-} \mathrm{Rag} 1^{-1-}(12.7 \%)$ than in $\mathrm{Rag}^{-/-}(20.3 \%)$ littermate thymus (Figure 5B). After anti-CD3 treatment, the $\mathrm{Shh}^{-1-} \mathrm{Rag} 1^{-1-}$ thymocytes expanded and differentiated to DP faster than the anti-CD3-treated control Rag1 ${ }^{-1-}$ thymocytes (Figure 5C). The proportion of DP cells was increased from $16.1 \%$ in the Rag1 $1^{-1-}$ FTOC to $25.3 \%$ in the $\mathrm{Shh}^{-/-} \mathrm{Rag}^{-/-}$ FTOC. As expected, anti-CD3 treatment stimulated proliferation, and the proportion of thymocytes in $\mathrm{S}+\mathrm{G} 2 / \mathrm{M}$ was increased to $30.8 \%$ in the anti-CD3-treated $\mathrm{Shh}^{-1-} \mathrm{Rag} 1^{-1-}$ FTOC and $27.3 \%$ in the anti-CD3-treated Rag $1^{-/-}$littermate FTOC. To test whether Gli2 functions downstream of Shh at this stage of thymocyte development, we also compared differentiation to DP cell in anti-CD3-treated Gli2 ${ }^{-1-}$ Rag1 ${ }^{-1-}$ FTOC and littermate Rag1 $1^{-1-}$ FTOC. The anti-CD3-treated Gli2 $2^{-1-} \mathrm{Rag} 1^{-1-}$ FTOC differentiated more quickly than their Rag1 ${ }^{-1-}$ littermate counterparts, and in a typical experiment, $28.9 \%$ of thymocytes were DP in the Gli2 $2^{-l-} \mathrm{Rag}^{-/-}$FTOC, compared with $16.4 \%$ in littermate Rag1 ${ }^{-1-}$ FTOC (Figure 5D), confirming that Gli2 is downstream of Shh as a negative regulator of differentiation and that it functions as an activator of transcription at this developmental stage.

The accelerated differentiation to DP in the anti-CD3-treated $\mathrm{Shh}^{-1-} \mathrm{Rag} 1^{-1-}$ FTOC appeared to contrast with the phenotype of the E16.5 $\mathrm{Shh}^{-1-}$ thymus, which like the E16.5 $\mathrm{Gli}^{-/-}$thymus, contained fewer DP cells than WT. ${ }^{18}$ It demonstrates that Shh is a negative regulator of pre-TCR-induced differentiation to DP, and therefore indicates that in the E16.5 $\mathrm{Shh}^{-1-}$ thymus, as seen in the E16.5 Gli2 ${ }^{-1-}$ thymus, the reduction in DP cells was the result of an earlier effect on thymocyte development.

Given that T lineage-specific conditional deletion of Smo from Rag-deficient thymocytes has been previously shown to have no effect on differentiation to DP on anti-CD3 treatment, ${ }^{22}$ it was possible that the effect of Shh deletion on thymocyte differentiation was indirect via another cell type, and not the result of reduction of Hh pathway activation in developing thymocytes. To test this, we treated FTOC from Gli $2 \Delta \mathrm{N}_{2} \operatorname{Rag}^{-1-}$ or Gli $2 \Delta \mathrm{C}_{2} \operatorname{Rag} 1^{-/-}$embryos and their respective Rag $1^{-/-}$littermates for 3 days with anti-CD3, to follow the differentiation of thymocytes in which Hh signal transduction was either specifically activated or specifically repressed.

In the case of the Gli $2 \Delta \mathrm{N}_{2} \mathrm{Rag}^{-/-}$FTOC, where Hh signaling is constitutively active in thymocytes, after treatment with antiCD3 both thymocyte number and pre-TCR-induced differentiation to DP cell were significantly reduced compared with $\mathrm{Rag} 1^{-/-}$ littermates (Figure 6A). In the Gli $2 \Delta \mathrm{N}_{2} \operatorname{Rag} 1^{-1-}$ FTOC, $7.2 \%$ of thymocytes were DP compared with $23.3 \%$ in the Rag $1^{-1-}$ control FTOC (Figure 6A). This reduction in anti-CD3-induced differentiation showed that Hh pathway activation inhibited pre-TCR signaling in a thymocyte-autonomous manner.

We measured MAPKinase pathway activation on pre-TCR signal transduction, using a FACS-based assay ${ }^{29}$ to compare icERK phosphorylation between Gli $2 \Delta \mathrm{N}_{2} \mathrm{Rag} 1^{-/-}$and Rag1 $1^{-/-}$thymocytes stimulated with anti-CD3 (Figure 6B). On pre-TCR stimulation, there was a clear shift in icphospho-ERK levels in the Rag1 $1^{-1-}$ thymocytes, with an approximately 2 -fold increase in mean fluorescence intensity. In contrast, the shift in anti-icphospho-ERK fluorescence was negligible in the Gli2 $\Delta \mathrm{N}_{2} \mathrm{Rag}^{-1-}$ thymocytes (Figure $6 \mathrm{~B}$ ) on pre-TCR stimulation.

Thymocyte-specific repression of $\mathrm{Hh}$ signaling in the Gli2 $\Delta \mathrm{C}_{2} \mathrm{Rag}^{-1-}$ FTOC had the opposite effect on pre-TCRinduced differentiation to DP, and promoted the transition. The proportion of DP cells in the anti-CD3-treated $\mathrm{Gli}_{2} \Delta \mathrm{C}_{2} \mathrm{Rag}^{-/-}$ FTOC was increased to $39.4 \%$, compared with $28.1 \%$ in the control anti-CD3-treated Rag1 ${ }^{-1-}$ FTOC (Figure 6C), but there was no significant difference in thymocyte number between the 2 genotypes of FTOC (Figure 6D). As expected from the Gli2 $\Delta \mathrm{N}_{2} \mathrm{Rag} 1^{-/-}$ experiment, icERK phosphorylation was increased on pre-TCR stimulation of Gli2 $\Delta \mathrm{C}_{2} \mathrm{Rag}^{-/-}$thymocytes compared with Rag1 $1^{-/-}$ littermate thymocytes (Figure 6E).

Thus, the fact that constitutive repression or activation of $\mathrm{Hh}$ signaling in thymocytes has opposing effects on pre-TCR-induced differentiation to DP confirms that $\mathrm{Hh}$ signaling is a direct negative regulator of pre-TCR-induced differentiation via the MAPkinase cascade.

\section{Identification of transcriptional targets of pre-TCR signal transduction}

To identify genes that are transcriptionally targeted on pre-TCR signal transduction under physiologic conditions, or on repression of Hh signaling, we used a QRT-PCR array approach to profile the expression of 84 genes representative of different signal transduction pathways. RNA was prepared from control and anti-CD3treated thymocytes purified from Gli2 $\Delta \mathrm{C}_{2} \operatorname{Rag} 1^{-/-}$and $\mathrm{Rag} 1^{-/-}$ littermate thymi for QRT-PCR analysis. We repeated this experiment 3 times, with independent groups of littermate mice, and identified genes whose transcription was significantly altered by pre-TCR signal transduction (Figure 7). This strategy identified 6 genes that were up-regulated on anti-CD3 treatment, and that were not differentially regulated between $\mathrm{Gli} 2 \Delta \mathrm{C}_{2} \operatorname{Rag} 1^{-/-}$and $\mathrm{Rag} 1^{-/-}$ thymocytes: the TCR signal modulator $C D 5$, the transcription factor $T c f 7$, the EGR1-binding protein, Nab2, the antiapoptotic factor Birc3, Fas ligand, and the transcriptional regulator Nrip1 (Figure 7A). The identification of CD5 and Tcf7 thus validated the experimental approach, as cell-surface CD5 is known to be up-regulated on pre-TCR signal transduction ${ }^{36}$ and Tcf7 expression is increased on pre-TCR signaling. ${ }^{37}$ The up-regulation of the EGR1-binding protein, Nab2, is of interest, given that EGR1 promotes thymocyte development at $\beta$-selection. ${ }^{38,39}$ 
A

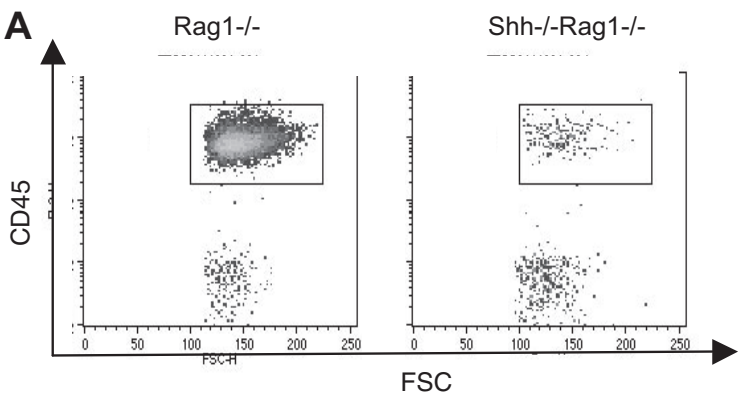

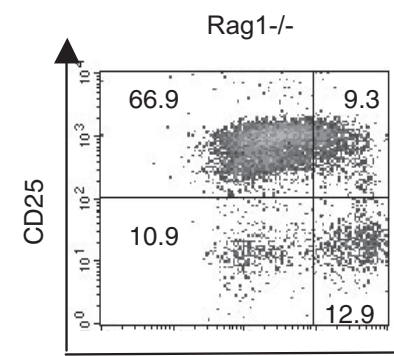

Shh-/-Rag1-/-
B

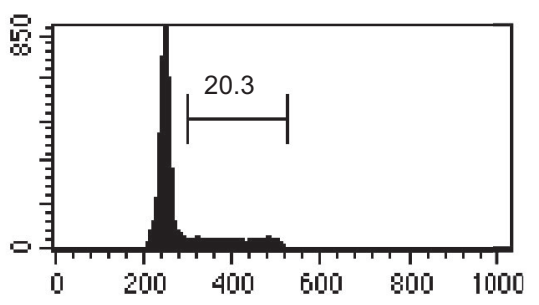

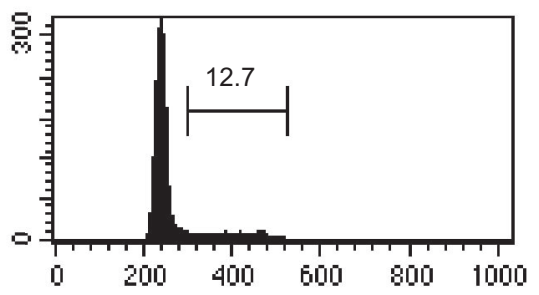

Propidium lodide

C

FTOC + anti-CD3

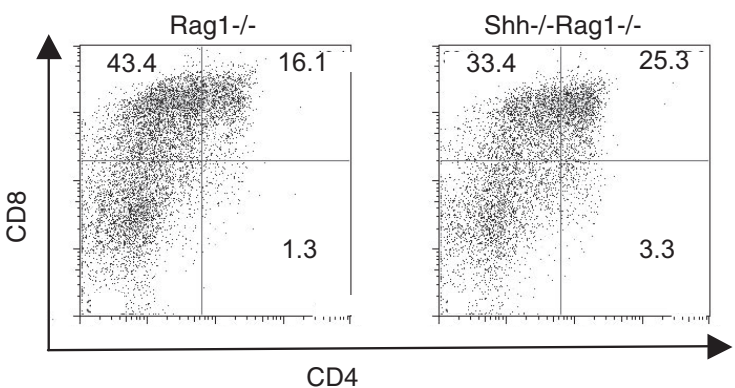

D

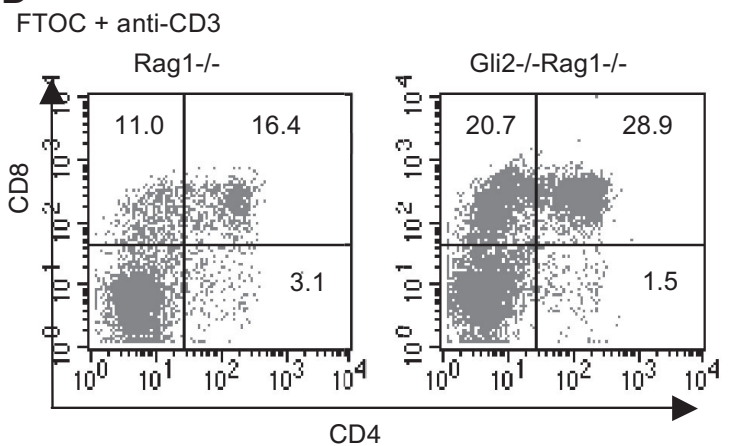

Shh-/-Rag1-/-

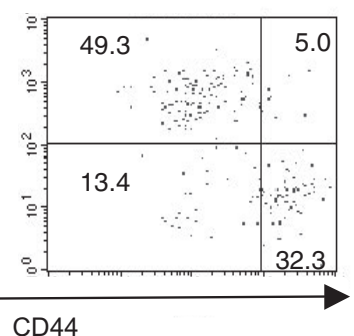

CD44 

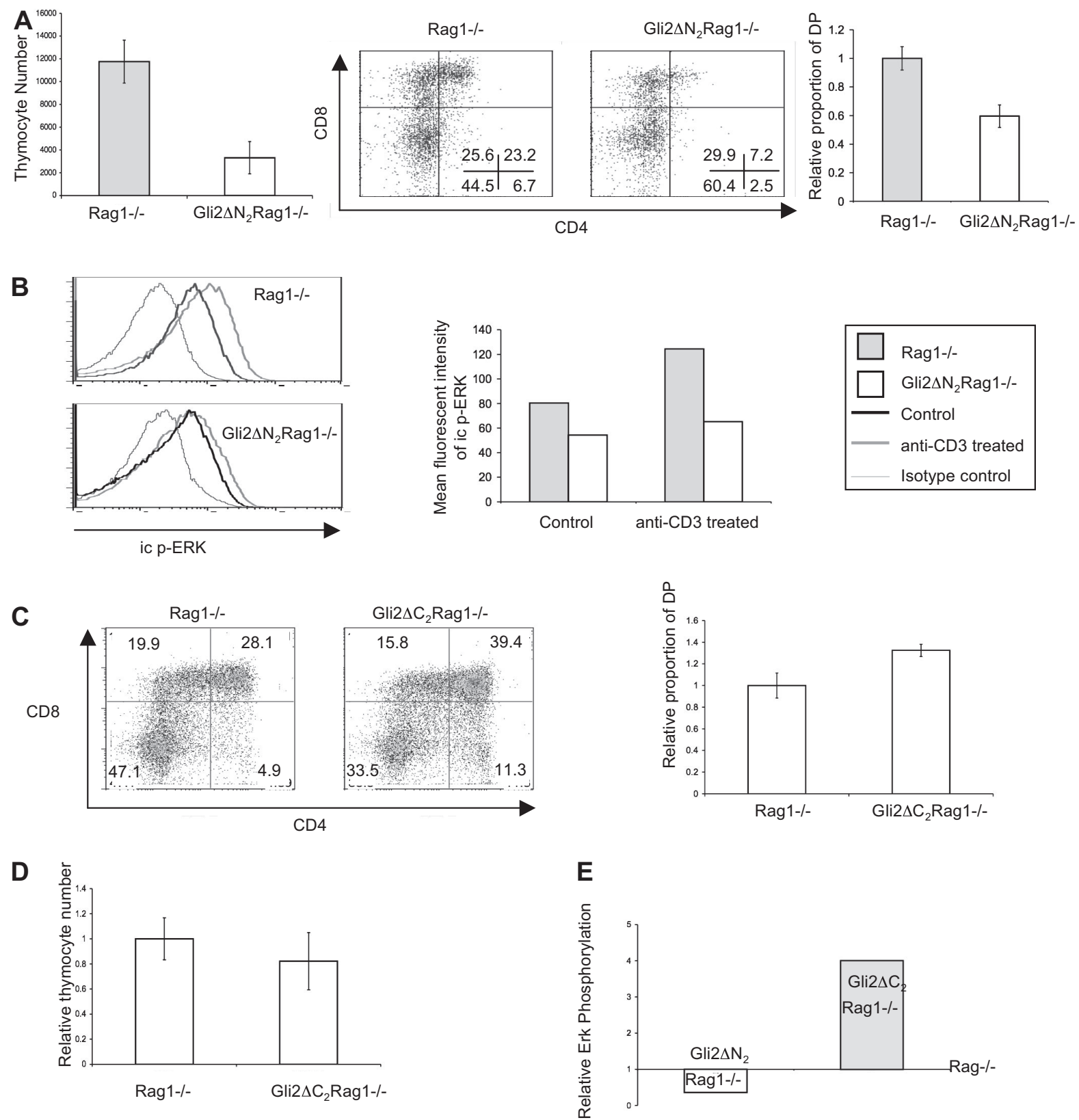

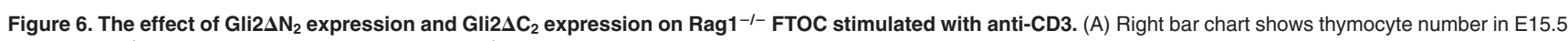
Gli $\Delta \mathrm{N}_{2}$ Rag1 $^{-1-}$ FTOC $(n=5)$ and littermate Rag1 ${ }^{-1-}$ FTOC $(n=4)$, after treatment for 3 days with $1 \mu \mathrm{g} / \mathrm{mL}$ anti-CD3 mab. The difference was statistically significant $(P=.008)$. Dot plots show CD4 and CD8 expression on Gli2 $\Delta \mathrm{N}_{2} \operatorname{Rag}_{1^{-1-}} \mathrm{FTOC}(\mathrm{n}=5)$ and littermate Rag1 ${ }^{-l-} \mathrm{FTOC}(\mathrm{n}=4)$, after treatment for 3 days with $1 \mu \mathrm{g} / \mathrm{mL}$ anti-CD3 mab. Left bar chart shows the relative proportion of DP cells in the same experiments. The difference between $\mathrm{Gli}_{1} \Delta \mathrm{N}_{2}$ Rag $1^{-l-}$ and littermate Rag $1^{-l-}$ is significant $(P=.009)$. Error bars show SD. (B) ERK phosphorylation in anti-CD3-treated Rag $1^{-1-}$ and Glis $\mathrm{N}_{2}$ Rag $1^{-/-}$thymocytes. Histograms of icphospho-ERK levels in control (untreated) and anti-CD3-treated $\left(5 \times 10^{6} \mathrm{cells} / \mathrm{mL}\right.$ activated with $10 \mu \mathrm{g} / \mathrm{mL}$ anti-CD3 mab cross-linked with biotinylated anti-hamster IgG for 2 minutes) thymocytes from Rag1 ${ }^{-1-}$ and

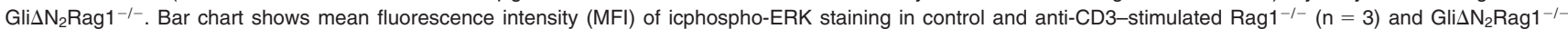

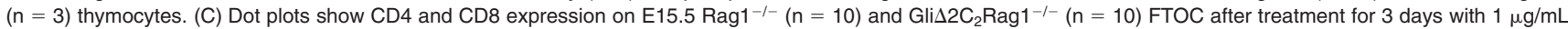
anti-CD3 mab. Bar chart shows the relative proportion of DP cells for anti-CD3-treated Gli2 $\Delta \mathrm{C}_{2}$ Rag $^{-1-}$ FTOC and littermate Rag1 ${ }^{-1-}$ FTOC. The difference is significant $(P=.001)$. Error bars show SD. (D) Relative thymocyte number in Gli2 $\Delta \mathrm{C}_{2} \mathrm{Rag}^{-1-} \mathrm{FTOC}$ and littermate Rag1 $1^{-1-} \mathrm{FTOC}, 3$ days after anti-CD3 treatment. There was no significant difference. Error bars show SD. (E) Relative change in ERK phosphorylation in anti-CD3-treated Gli2 $\Delta \mathrm{C}_{2}$ Rag1 $1^{-1-}\left(5 \times 10^{6} \mathrm{cells} / \mathrm{mL}\right.$ activated with $10 \mu \mathrm{g} / \mathrm{mL}$ anti-CD3 mab cross-linked with biotinylated anti-hamster IgG for 2 minutes; and $G$ li2 $2 \Delta \mathrm{N}_{2} R a g 1^{-/-}, n=3$ ) thymocytes, normalized to that of their Rag1 $1^{-1-}$ littermate controls. Error bars show SE.

Telomerase reverse transcriptase (Tert; itself a transcriptional target of Myc), the antiapoptotic factor Bircla, Cadherin 1, and HoxAl.

\section{Hh signaling maintains FoxA2 expression on pre-TCR signal transduction}

We then looked for genes that were differentially regulated by the pre-TCR on repression of Hh signaling compared with WT, and interestingly identified only one significant transcriptional difference: FoxA2 ( $P=.04$; Figure $7 \mathrm{C})$. There were no significant differences in gene expression between $\mathrm{Rag} 1^{-1-}$ and Gli2 $\Delta \mathrm{C}_{2} \mathrm{Rag}^{-1-}$ thymocytes before anti-CD3 treatment, indicating that the difference in transcription of FoxA2 was a consequence of pre-TCR signal transduction. On anti-CD3 treatment, there was a 6-fold down-regulation of the transcription factor 
A

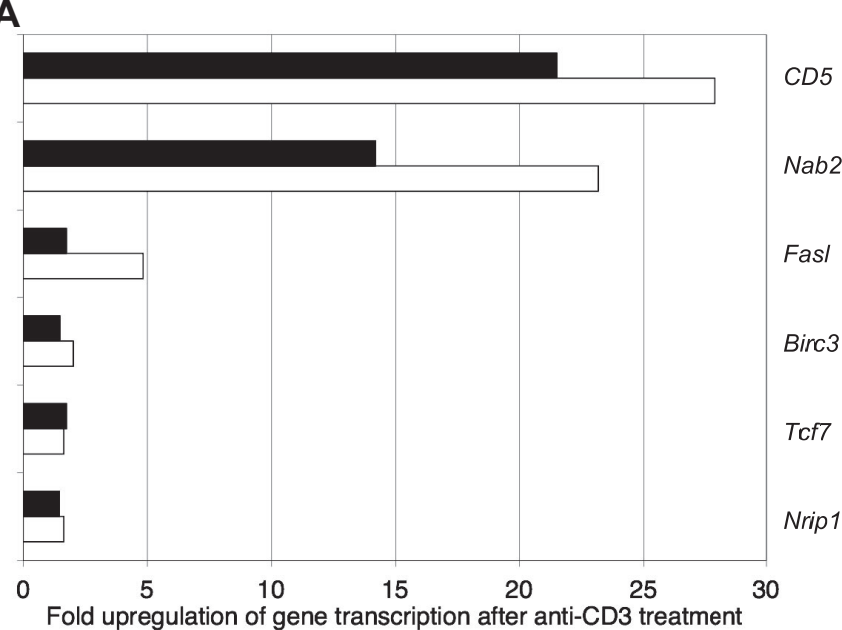

B
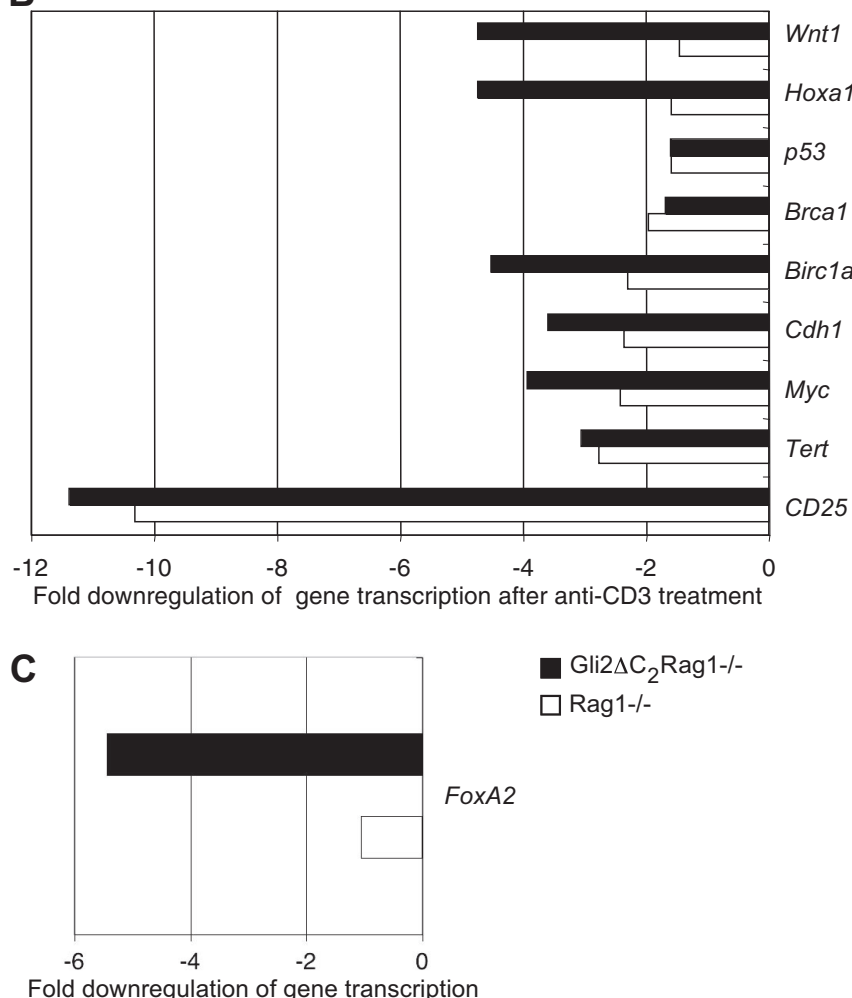

Fold downregulation of gen
after anti-CD3 treatment

FoxA2 in the Gli2 $\Delta \mathrm{C}_{2} \mathrm{Rag}^{-/-}$only. FoxA2 is essential for mouse development and FoxA2-1- embryos die at E10 with defects in node, notochord, neural tube, and gut. ${ }^{43,44}$ In the mouse floor plate, FoxA2 is a Shh target gene and the FoxA2 enhancer contains a Gli-binding site. ${ }^{45}$ Our experiment indicates that in thymocytes, Hh signaling maintains FoxA2 expression during pre-TCR signal transduction, as when $\mathrm{Hh}$ pathway activation was inhibited by transgenic Gli2 $\Delta \mathrm{C}_{2}$ expression, FoxA2 was down-regulated.

\section{Discussion}

Here we show that Shh signaling, via Gli2, promotes thymocyte development before pre-TCR signal transduction, but that Shh and
Figure 7. PCR array analysis of gene transcription in Gli2 $\Delta \mathrm{C}_{2}$ Rag1-/- control and anti-CD3-treated Rag1 $^{-1-}$ and $\mathrm{Gli}_{2} \Delta \mathrm{C}_{2}$ Rag1 $^{-l-}$ thymocytes. Bars show average fold change in gene transcription on anti-CD3 treatment, relative to transcription in untreated samples. Values were calculated by dividing the average gene transcription in the treated samples (Rag1 ${ }^{-l-}+$ anti-CD3 or Gli2 $\Delta \mathrm{C}_{2} \mathrm{Rag}^{-/-}+$anti-CD3) by the corresponding ones from the control samples (Rag1 ${ }^{-1-}$ or Gli2 $\Delta \mathrm{C}_{2} \mathrm{Rag}^{-1-}$ ). $(A, B)$ All genes shown exhibited statistically significant change after anti-CD3 treatment in $\mathrm{Rag} 1^{-1-}$ and/or $\mathrm{Gli}_{2} \Delta \mathrm{C}_{2} \mathrm{Rag}^{-/-}$thymocytes. (A) Genes significantly upregulated after anti-CD3 treatment. $P$ values for Rag1 ${ }^{-1-}$ : Nrip1, $P=.02 ;$ Tcf7, $P=.06 ;$ Birc3, $P=.02 ;$ Fasl, $P=.04 ;$ Nab2, $P=.002 ;$ and $C D 5, P=.004 . P$ values for Gli2 $\Delta \mathrm{C}_{2}$ Rag1 $^{-1-}$ : Nrip1, $P=.005 ;$ Tcf7, $P=.03 ;$ Birc3, $P=.5 ;$ Fasl, $P=.4 ;$ Nab2, $P=.04$; and $C D 5, P=.02$. (B) Genes significantly down-regulated after anti-CD3 treatment. $P$ values for Rag1 ${ }^{-1-}: C D 25, P=.002$; Tert, $P=.07 ;$ Myc, $P=.01 ;$ Cdh1, $P=.04 ;$ Birc1a, $P=.05$; Brca1, $P=.007 ; p 53, P=.1 ;$ Hoxa1, $P=.005$; and Wnt1, $P=.03$. $P$ values for $\mathrm{Gli}_{2} \Delta \mathrm{C}_{2} \mathrm{Rag}^{-1-}: C D 25$, $P=.01 ;$ Tert, $P=.01 ;$ Myc, $P=.06 ; C d h 1, P=.08$; Birc1a, $P=.2 ;$ Brca1, $P=.04 ; p 53, P=.04 ;$ Hoxa1, Gli2 $\Delta \mathrm{C}_{2}$ Rag1-/- $\quad P=.2$; and $W n t 1, P=.3$. (C) Change in transcription of FoxA2 after anti-CD3 treatment. Difference in change in transcription of FoxA2 was significant between genotypes, $P=.05$.
Gli2 are negative regulators of pre-TCR signal transduction and thymocyte differentiation at the transition from DN to DP cell. Analysis of $\mathrm{Shh}^{-1-}$, $\mathrm{Gli}^{-1-}$, and conditional Smo-deficient thymi ${ }^{18,21,22}$ has previously shown that $\mathrm{Hh}$ signaling regulates the differentiation, survival, and proliferation of the earliest DN1 and DN2 thymocyte populations, and this analysis of thymocyte development in Gli2-deficient embryos also demonstrated the nonredundant involvement of Gli2 at this developmental stage. The transition from DN1 to DN2 was reduced in the Gli2 $2^{-1-}$ thymus, but we did not detect an influence of Gli2 deficiency on DN1 or DN2 survival or proliferation. This suggests that although Gli2 is an essential mediator of Shh-induced differentiation at this developmental stage, it is not necessary for $\mathrm{Shh} / \mathrm{Smo}$-induced survival or proliferation, and that there is redundancy between Gli family members for these functions of Hh signaling in DN1 and DN2 thymocytes. 
The function of Hh signaling at the transition from DN to DP has been controversial, ${ }^{1,18,22}$ but here we showed, using many different mouse models, that $\mathrm{Hh}$ signaling negatively regulates the pre-TCR signal for differentiation to DP cell. When Hh pathway activation was reduced, in the $\mathrm{Shh}^{-1-} \mathrm{Rag} 1^{-1-}$, Gli2 ${ }^{-1-} \operatorname{Rag} 1^{-1-}$, and $\mathrm{Gli} 2^{-l-}$ thymus, or by $\mathrm{T}$ lineage-specific transgenic expression of a transcriptional-repressor form of Gli2 (Gli2 $\left.\Delta \mathrm{C}_{2}\right)$, differentiation to DP cell after pre-TCR signal transduction was increased. We observed increased production of DP cells in the E17.5 Gli2 $2^{-1-}$ thymus, and in anti-CD3-treated $\mathrm{Shh}^{-1-} \operatorname{Rag} 1^{-/-}, \mathrm{Gli}^{-/-} \mathrm{Rag}^{-1-}$, and Gli $2 \Delta \mathrm{C}_{2} \operatorname{Rag}^{-1-}$ FTOC, and in the adult Gli2 $2 \Delta \mathrm{C}_{2}$ thymus after depletion of the DP pool by HC treatment. In contrast, when $\mathrm{Hh}$ signaling was constitutively activated in thymocytes by transgenic expression of a constitutive transcriptional activator form of Gli2 $\left(\mathrm{Gli} 2 \Delta \mathrm{N}_{2}\right)$, the production of DP cells was decreased, both in anti-CD3-treated Gli2 $\Delta \mathrm{N}_{2} \operatorname{Rag} 1^{-1-}$ FTOC, and in adult HC-treated Gli2 $\Delta \mathrm{N}_{2}$ thymus.

The fact that $\mathrm{Shh}^{-/-} \mathrm{Rag} 1^{-/-}$and $\mathrm{Gli} 2^{-/-} \mathrm{Rag} 1^{-/-}$FTOCs both showed increased differentiation to DP cell on anti-CD3 treatment, whereas the $\mathrm{Gli}^{-1-} \mathrm{Rag} 1^{-/-}$differentiated less efficiently, ${ }^{21}$ indicated that Gli2 functions as a transcriptional activator downstream of Shh at this developmental stage, and therefore that Gli3 functions as a transcriptional repressor.

The experiments presented here seem to conflict with a previous analysis of a conditional $\mathrm{T}$ lineage-specific Smo knockout model, which was interpreted as showing that Hh does not influence thymocyte development after the DN2 stage. ${ }^{22}$ In that study, Smo deficiency greatly reduced survival, proliferation, and differentiation at the DN1 to DN2 transition, resulting in a smaller thymus with fewer DP cells than WT. However, in vivo anti-CD3-induced differentiation of Rag2 $2^{-1-}$ thymocytes produced similar numbers of DP cells, in both conditional Smo-deficient mice and littermates. ${ }^{22}$ Taken together, it therefore seems that Smo deficiency did in fact increase differentiation from DN to DP stage, as the small Smo-deficient Rag2 $2^{-1-}$ thymus was able to "catch up" in terms of DP production and number with its control Rag2 $2^{-/-}$littermate thymus on transduction of the pre-TCR signal. Given that Smo is a nonredundant component of the Hh pathway, essential for signal transduction, ${ }^{46}$ its conditional deletion should completely abrogate $\mathrm{Hh}$ pathway activation in T-lineage cells. Thus, in the adult steady-state thymus, it would have been difficult to detect the effect of simultaneous loss of both positive and negative regulation of T-cell development by Smo, as the profound effects of complete loss of the earlier positive Hh signal would mask the effects of loss of the later negative regulation of pre-TCR-induced differentiation. By analysis of mouse mutants in components of the signaling pathway, which are functionally at least partially redundant (eg, redundancy between Gli proteins or between Hh family members), we have been able to detect the influence of $\mathrm{Hh}$ signaling at multiple stages of development. This has also been facilitated by following thymocyte development in situations where the transition from DN to DP is more or less synchronized, such as on E16.5 and E17.5 of embryonic development, in anti-CD3-treated Rag1 $1^{-1-}$ FTOC, and in adult thymus as it recovers from HC depletion.

It might seem surprising that although Shh provides positive signals for survival, differentiation, and proliferation of the early DN thymocyte populations, ${ }^{18,22}$ it then "switches" to function as a negative regulator of thymocyte differentiation at later stages of thymocyte development. However, similar opposing functions for $\mathrm{Hh}$ signaling have been described in the development of other tissues, such as gut and retina, ${ }^{47,48}$ and are consistent with the action of a morphogen, which can specify multiple cell fates. The outcome of Hh signal transduction in a cell will depend on not only strength and duration of the signal (determined in part by the position of the cell relative to the source of $\mathrm{Hh}$ ), but also the intracellular and extracellular context of signal transduction. In the future, it will be important to understand the context-dependent molecular machinery that accounts for these opposing outcomes of Hh pathway activation at different stages of thymocyte development.

The way in which Hh pathway activation in thymocytes reduced differentiation to DP is not clear, but given that ERK phosphorylation on CD3 ligation was reduced, it seems that $\mathrm{Hh}$ pathway activation modulated the pre-TCR signal. The mechanism of modulation remains to be investigated, and it seems likely that it is the result of Hh-induced transcriptional changes in the developing thymocyte.

We have identified novel transcriptional targets of pre-TCR signal transduction: genes up-regulated include the EGR1-binding protein, $\mathrm{Nab2}$, the antiapoptotic factor and caspase-inhibitor Birc3, and the transcriptional regulator Nripl. In addition, we found down-regulation of genes known to be involved in thymocyte development, such as Wnt-1, Brca-1, p53, and Myc, and genes, that to our knowledge, have not previously been studied in thymocytes, such as the antiapoptotic factor Bircla, and the homeobox gene HoxA1. Use of the Gli $2 \Delta \mathrm{C}_{2}$ transgenic allowed us to look for genes that, on pre-TCR signal transduction, are differentially regulated by inhibition of $\mathrm{Hh}$ signaling in developing thymocytes. Interestingly, this approach demonstrated that the physiologic level of Hh signaling in thymocytes maintains expression of FoxA2, encoding a forkhead box transcription factor and known Hh target gene in other tissues, on pre-TCR signal transduction. As the FoxA gene family members are regulators of many aspects of mammalian development, ${ }^{49}$ it will be important in the future to assess their function in thymocyte differentiation and their potential role in differentiation to DP cell, as a negative regulator downstream of $\mathrm{Hh}$.

\section{Acknowledgments}

We thank D. Davies (Cancer Research UK) for cell sorting, C. Hui for Gli2 $2^{+/-}$mice, and P. Beachy for the $\mathrm{Shh}^{+/-}$mice.

This work was funded by Medical Research Council (MRC, London, United Kingdom), Biotechnology and Biological Sciences Research Council (BBSRC, Swindon, United Kingdom), Wellcome Trust (London, United Kingdom), and Leukaemia Research Foundation (LRF, London, United Kingdom). N.J.R. is supported by a Foulkes Foundation Fellowship.

\section{Authorship}

Contribution: N.J.R. and T.C. designed research and wrote the paper; N.J.R., A.L.H.-T., and T.C. performed research, collected, analyzed, and interpreted data, and performed statistical analysis; and A.L.F., S.E.R., S.V.O., and J.T.D. performed research.

Conflict-of-interest disclosure: The authors declare no competing financial interests.

Correspondence: Tessa Crompton, Immunobiology Unit, UCL Institute of Child Health, 30 Guilford St, London WC1N 1EH, United Kingdom; e-mail: t.crompton@ich.ucl.ac.uk. 


\section{References}

1. Crompton T, Outram SV, Hager-Theodorides AL. Sonic hedgehog signalling in T-cell development and activation. Nat Rev Immunol. 2007;7:726735.

2. Ingham PW, Placzek M. Orchestrating ontogenesis: variations on a theme by sonic hedgehog. Nat Rev Genet. 2006;7:841-850.

3. Ingham PW, McMahon AP. Hedgehog signaling in animal development: paradigms and principles. Genes Dev. 2001;15:3059-3087.

4. Jia J, Jiang J. Decoding the Hedgehog signal in animal development. Cell Mol Life Sci. 2006;63: 1249-1265.

5. Bhardwaj G, Murdoch B, Wu D, et al. Sonic hedgehog induces the proliferation of primitive human hematopoietic cells via BMP regulation. Nat Immunol. 2001;2:172-180.

6. Outram SV, Varas A, Pepicelli CV, Crompton T. Hedgehog signaling regulates differentiation from double-negative to double-positive thymocyte. Immunity. 2000;13:187-197.

7. Hooper JE, Scott MP. Communicating with Hedgehogs. Nat Rev Mol Cell Biol. 2005;6:306 317.

8. Lum L, Beachy PA. The Hedgehog response network: sensors, switches, and routers. Science. 2004;304:1755-1759.

9. Koebernick K, Pieler T. Gli-type zinc finger proteins as bipotential transducers of Hedgehog signaling. Differentiation. 2002;70:69-76.

10. Matise MP, Joyner AL. Gli genes in development and cancer. Oncogene. 1999;18:7852-7859.

11. Park HL, Bai C, Platt KA, et al. Mouse Gli1 mutants are viable but have defects in SHH signaling in combination with a Gli2 mutation. Development. 2000;127:1593-1605.

12. Aza-Blanc P, Lin HY, Ruiz i Altaba A, Kornberg TB. Expression of the vertebrate Gli proteins in Drosophila reveals a distribution of activator and repressor activities. Development. 2000;127: 4293-4301.

13. Sasaki H, Nishizaki Y, Hui C, Nakafuku M Kondoh H. Regulation of Gli2 and Gli3 activities by an amino-terminal repression domain: implication of Gli2 and Gli3 as primary mediators of Shh signaling. Development. 1999;126:3915-3924.

14. Mo R, Freer AM, Zinyk DL, et al. Specific and redundant functions of Gli2 and Gli3 zinc finger genes in skeletal patterning and development. Development. 1997;124:113-123.

15. Bai CB, Auerbach W, Lee JS, Stephen D, Joyner AL. Gli2, but not Gli1, is required for initial Shh signaling and ectopic activation of the Shh pathway. Development. 2002;129:4753-4761.

16. Wang B, Fallon JF, Beachy PA. Hedgehogregulated processing of Gli3 produces an anterior/posterior repressor gradient in the developing vertebrate limb. Cell. 2000;100:423-434.

17. Aifantis I, Mandal M, Sawai K, Ferrando A, Vilimas T. Regulation of T-cell progenitor survival and cell-cycle entry by the pre-T-cell receptor. Immunol Rev. 2006;209:159-169.

18. Shah DK, Hager-Theodorides AL, Outram SV, Ross SE, Varas A, Crompton T. Reduced thymocyte development in sonic hedgehog knockout embryos. J Immunol. 2004;172:2296-2306.
19. Sacedón R, Varas A, Hernandez-Lopez C, et al. Expression of hedgehog proteins in the human thymus. J Histochem Cytochem. 2003;51:15571566.

20. Rowbotham NJ, Hager-Theodorides AL, Cebecauer M, et al. Activation of the Hedgehog signaling pathway in T lineage cells inhibits TCR repertoire selection in the thymus and peripheral T cell activation. Blood. 2007;109:3757-3766.

21. Hager-Theodorides AL, Dessens JT, Outram SV, Crompton $\mathrm{T}$. The transcription factor $\mathrm{Gli} 3$ regulates differentiation of fetal CD4- CD8- doublenegative thymocytes. Blood. 2005;106:12961304.

22. El Andaloussi A, Graves S, Meng F, Mandal M Mashayekhi M, Aifantis I. Hedgehog signaling controls thymocyte progenitor homeostasis and differentiation in the thymus. Nat Immunol. 2006; 7:418-426.

23. Outram SV, Hager-Theodorides AL, Shah DK, et al. Indian hedgehog (Ihh) both promotes and restricts thymocyte differentiation. Blood. 2009;113 2217-2228.

24. Gutiérrez-Frías C, Sacedon R, Hernandez-Lopez $\mathrm{C}$, et al. Sonic hedgehog regulates early human thymocyte differentiation by counteracting the IL-7-induced development of CD34+ precursor cells. J Immunol. 2004;173:5046-5053.

25. Chiang $C$, Litingtung $Y$, Lee $E$, et al. Cyclopia and defective axial patterning in mice lacking Sonic hedgehog gene function. Nature. 1996;383:407413.

26. Rowbotham NJ, Furmanski AL, Hager-Theodorides $\mathrm{AL}$, et al. Repression of hedgehog signal transduction in T-lineage cells increases TCR-induced activation and proliferation. Cell Cycle. 2008;7: 904-908.

27. Hager-Theodorides AL, Rowbotham NJ, Outram SV, Dessens JT, Crompton T. Beta-selection: abundance of TCRbeta-/gammadelta- CD44 CD25- (DN4) cells in the foetal thymus. Eur J Immunol. 2007;37:487-500.

28. Gounari F, Chang R, Cowan J, et al. Loss of adenomatous polyposis coli gene function disrupts thymic development. Nat Immunol. 2005;6:800809.

29. Costello PS, Nicolas RH, Watanabe Y, Rosewell I, Treisman R. Ternary complex factor SAP-1 is required for Erk-mediated thymocyte positive selection. Nat Immunol. 2004;5:289-298.

30. Rodewald HR, Awad K, Moingeon P, et al. FC gamma RII/III and CD2 expression mark distinct subpopulations of immature CD4-CD8- murine thymocytes: in vivo developmental kinetics and T cell receptor beta chain rearrangement status. J Exp Med. 1993;177:1079-1092.

31. Sasada T, Reinherz EL. A critical role for CD2 in both thymic selection events and mature $T$ cell function. J Immunol. 2001;166:2394-2403.

32. Chaffin KE, Beals CR, Wilkie TM, Forbush KA, Simon MI, Perlmutter RM. Dissection of thymocyte signaling pathways by in vivo expression of pertussis toxin ADP-ribosyltransferase. EMBO J. 1990;9:3821-3829.

33. Crompton $\mathrm{T}$, Ohashi $\mathrm{P}, \mathrm{Schneider} \mathrm{SD}$, Pircher $\mathrm{H}$, MacDonald HR. A cortisone sensitive CD3low subset of CD4+CD8- thymocytes represents an intermediate stage in intrathymic repertoire selection. Int Immunol. 1992;4:153-161.

34. Mombaerts P, lacomini J, Johnson RS, Herrup K, Tonegawa S, Papaioannou VE. RAG-1-deficient mice have no mature $B$ and T lymphocytes. Cell. 1992;68:869-877.

35. Levelt CN, Mombaerts P, Iglesias A, Tonegawa S, Eichmann K. Restoration of early thymocyte differentiation in T-cell receptor beta-chain-deficient mutant mice by transmembrane signaling through CD3 epsilon. Proc Natl Acad Sci U S A. 1993;90: 11401-11405.

36. Azzam HS, DeJarnette JB, Huang K, et al. Fine tuning of TCR signaling by CD5. J Immunol. 2001;166:5464-5472.

37. Goux D, Coudert JD, Maurice D, et al. Cooperating pre-T-cell receptor and TCF-1-dependent signals ensure thymocyte survival. Blood. 2005;106: 1726-1733.

38. Koltsova EK, Ciofani M, Benezra R, et al. Early growth response 1 and NF-ATc1 act in concert to promote thymocyte development beyond the beta-selection checkpoint. J Immunol. 2007;179: 4694-4703.

39. Carleton M, Haks MC, Smeele SA, et al. Early growth response transcription factors are required for development of CD4(-)CD8(-) thymocytes to the CD4(+)CD8(+) stage. J Immunol. 2002;168:1649-1658.

40. Jiang D, Lenardo MJ, Zuniga-Pflucker JC. p53 prevents maturation to the CD4+CD8+ stage of thymocyte differentiation in the absence of $\mathrm{T}$ cel receptor rearrangement. J Exp Med. 1996;183: 1923-1928.

41. Mulroy T, McMahon JA, Burakoff SJ, McMahon AP, Sen J. Wnt-1 and Wnt-4 regulate thymic cellularity. Eur J Immunol. 2002;32:967-971.

42. Mak TW, Hakem A, McPherson JP, et al. Brcal required for $\mathrm{T}$ cell lineage development but not TCR loci rearrangement. Nat Immunol. 2000;1: 77-82.

43. Ang SL, Rossant J. HNF-3 beta is essential for node and notochord formation in mouse development. Cell. 1994;78:561-574.

44. Weinstein DC, Ruiz i Altaba A, Chen WS, et al The winged-helix transcription factor HNF-3 beta is required for notochord development in the mouse embryo. Cell. 1994;78:575-588.

45. Sasaki H, Hui C, Nakafuku M, Kondoh H. A binding site for Gli proteins is essential for HNF-3beta floor plate enhancer activity in transgenics and can respond to Shh in vitro. Development. 1997; 124:1313-1322.

46. Zhang XM, Ramalho-Santos M, McMahon AP Smoothened mutants reveal redundant roles for Shh and Ihh signaling including regulation of $L / A$ asymmetry by the mouse node. Cell. 2001;105: 781-792.

47. Agathocleous M, Locker M, Harris WA, Perron M. A general role of hedgehog in the regulation of proliferation. Cell Cycle. 2007;6:156-159.

48. Neumann CJ. Hedgehogs as negative regulators of the cell cycle. Cell Cycle. 2005;4:1139-1140.

49. Friedman JR, Kaestner KH. The Foxa family of transcription factors in development and metabolism. Cell Mol Life Sci. 2006;63:2317-2328. 


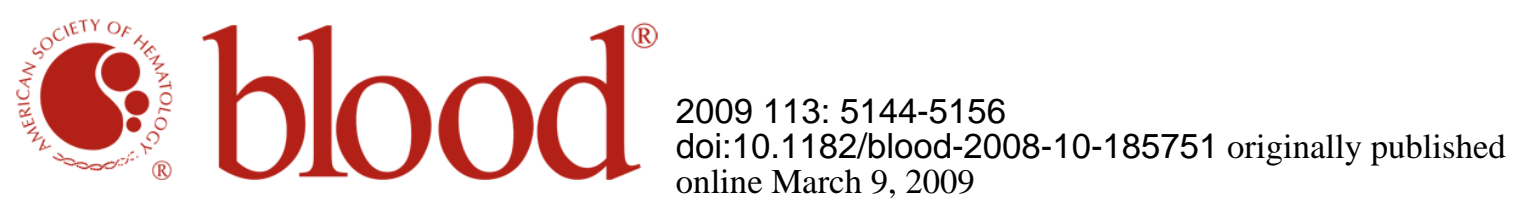

\section{Sonic hedgehog negatively regulates pre-TCR-induced differentiation by a Gli2-dependent mechanism}

Nicola J. Rowbotham, Ariadne L. Hager-Theodorides, Anna L. Furmanski, Susan E. Ross, Susan V. Outram, Johannes T. Dessens and Tessa Crompton

Updated information and services can be found at: http://www.bloodjournal.org/content/113/21/5144.full.html

Articles on similar topics can be found in the following Blood collections Immunobiology and Immunotherapy (5701 articles)

Information about reproducing this article in parts or in its entirety may be found online at: http://www.bloodjournal.org/site/misc/rights.xhtml\#repub_requests

Information about ordering reprints may be found online at:

http://www.bloodjournal.org/site/misc/rights.xhtml\#reprints

Information about subscriptions and ASH membership may be found online at: http://www.bloodjournal.org/site/subscriptions/index.xhtml 